Research review paper

\title{
Haploids: Constraints and opportunities in plant breeding
}

\author{
Sangam L. Dwivedi ${ }^{a}$, Anne B. Britt ${ }^{\mathrm{b}}$, Leena Tripathi ${ }^{\mathrm{c}}$, Shivali Sharma ${ }^{\mathrm{a}}$, \\ Hari D. Upadhyaya ${ }^{\text {a,d,e,f }}$, Rodomiro Ortiz ${ }^{\mathrm{g}, *}$ \\ a International Crops Research Institute for the Semi-Arid Tropics (ICRISAT), Patancheru, Telangana, 502324, India \\ ${ }^{\mathrm{b}}$ Department of Plant Biology, University of California, Davis, CA 95616, USA \\ c International Institute of Tropical Agriculture (IITA), Nairobi, P. O. Box 30709-00100, Kenya \\ d Department of Agronomy, Kansas State University, Manhattan, KS 66506, USA \\ e UWA Institute of Agriculture, University of Western Australia, Crawley WA 6009, Australia \\ ${ }^{\mathrm{f}}$ Department of Biology, University of Louisiana at Lafayette, 300 E. St. Mary Blvd, 108 Billeaud Hall, Lafayette, LA 70504, USA \\ ${ }^{g}$ Swedish University of Agricultural Sciences (SLU), Department of Plant Breeding, Sundsvagen 14 Box 101, 23053 Alnarp, Sweden
}

\section{A R T I C L E I N F O}

\section{Article history:}

Received 15 January 2015

Received in revised form 4 May 2015

Accepted 3 July 2015

Available online 9 July 2015

\section{Keywords:}

Accelerating plant breeding

Centromere-mediated genome elimination

Genetic transformation and androgenesis

Haploids and doubled haploids

In vitro gametic tissues and plant breeding

\begin{abstract}
A B S T R A C T
The discovery of haploids in higher plants led to the use of doubled haploid (DH) technology in plant breeding. This article provides the state of the art on DH technology including the induction and identification of haploids, what factors influence haploid induction, molecular basis of microspore embryogenesis, the genetics underpinnings of haploid induction and its use in plant breeding, particularly to fix traits and unlock genetic variation. Both in vitro and in vivo methods have been used to induce haploids that are thereafter chromosome doubled to produce DH. Various heritable factors contribute to the successful induction of haploids, whose genetics is that of a quantitative trait. Genomic regions associated with in vitro and in vivo DH production were noted in various crops with the aid of DNA markers. It seems that $\mathrm{F}_{2}$ plants are the most suitable for the induction of $\mathrm{DH}$ lines than $\mathrm{F}_{1}$ plants. Identifying putative haploids is a key issue in haploid breeding. $\mathrm{DH}$ technology in Brassicas and cereals, such as barley, maize, rice, rye and wheat, has been improved and used routinely in cultivar development, while in other food staples such as pulses and root crops the technology has not reached to the stage leading to its application in plant breeding. The centromere-mediated haploid induction system has been used in Arabidopsis, but not yet in crops. Most food staples are derived from genomic resources-rich crops, including those with sequenced reference genomes. The integration of genomic resources with DH technology provides new opportunities for the improving selection methods, maximizing selection gains and accelerate cultivar development. Marker-aided breeding and DH technology have been used to improve host plant resistance in barley, rice, and wheat. Multinational seed companies are using DH technology in large-scale production of inbred lines for further development of hybrid cultivars, particularly in maize. The public sector provides support to national programs or small-medium private seed for the exploitation of $\mathrm{DH}$ technology in plant breeding.
\end{abstract}

(C) 2015 Elsevier Inc. All rights reserved.

\section{Contents}

1. Introduction . . . . . . . . . . . . . . . . . . . . . . . . . . . . . . . . . . . . . . . . . . . 813

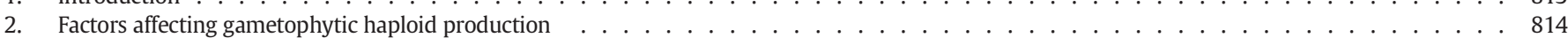

3. In vitro manipulation of gametic tissues for plant breeding . . . . . . . . . . . . . . . . . . . . . . . . . . . . . . . . . . . . . . . . . 815

3.1. Gametoclonal variation . . . . . . . . . . . . . . . . . . . . . . . . . . . . . . . . . . . . . . 815

3.2. Gametosomatic hybridization . . . . . . . . . . . . . . . . . . . . . . . . . . . . . . . . . . 815

3.3. Haploid protoplast . . . . . . . . . . . . . . . . . . . . . . . . . . . . . . . . . . . . . . 816

4. Molecular basis of microspore embryogenesis . . . . . . . . . . . . . . . . . . . . . . . . . . . . . . . . . . . . . . . . 816

5. Identifying putative haploids (focusing on recent advances in maize) . . . . . . . . . . . . . . . . . . . . . . . . . . 816

5.1. Plant morphology and stomatal chloroplast count . . . . . . . . . . . . . . . . . . . . . . . . . . . . . . . . . . . . 816

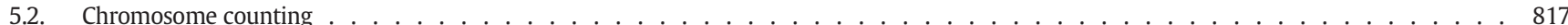

5.3. Flow cytometry . . . . . . . . . . . . . . . . . . . . . . . . . . . . . . . . . . . . . . . 817

5.4. Biochemical marker . . . . . . . . . . . . . . . . . . . . . . . . . . . . . . . . . . . . . 817

5.5. Molecular markers . . . . . . . . . . . . . . . . . . . . . . . . . . . . . . . . . . . 817

\footnotetext{
* Corresponding author.
}

E-mail address: rodomiro.ortiz@slu.se (R. Ortiz). 
6. Conventional methods to induce doubled haploids

7. Agrobacterium-mediated genetic transformation to androgenesis

8. Centromere-mediated genetic engineering to haploid induction . . . . . . . . . . . . . . . . . . . . . . . . . . . . . . . . . . . . 819

9. Insights into the genetics of haploid induction . . . . . . . . . . . . . . . . . . . . . . . . . . . . . . . . . . . . . . . . . 820

10. Trait fixation (heterosis) via anther culture . . . . . . . . . . . . . . . . . . . . . . . . . . . . . . . . . . . . . . 820

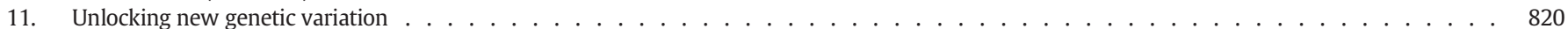

12. Accelerating crop breeding using doubled haploids, DNA markers, and data management . . . . . . . . . . . . . . . . . . . . . . . . . . . 821

12.1. Doubled haploids and marker assisted selection . . . . . . . . . . . . . . . . . . . . . . . . . . . . . . . . . . . . . . . . . . 821

12.2. Genomic selection using DHs . . . . . . . . . . . . . . . . . . . . . . . . . . . . . . . . . . . . . . . . . . 821

12.3. Establishing haploid induction facilities to support breeding programs . . . . . . . . . . . . . . . . . . . . . . . . . . . . 822

12.4. Integrated data management . . . . . . . . . . . . . . . . . . . . . . . . . . . . . . . . . . . . . . . . 822

13. Genetic gains through haploid breeding vis-à-vis other crossbreeding methods . . . . . . . . . . . . . . . . . . . . . . . . . . . . . . 823

14. Perspectives . . . . . . . . . . . . . . . . . . . . . . . . . . . . . . . . . . . . . . . 823

Acknowledgment . . . . . . . . . . . . . . . . . . . . . . . . . . . . . . . . . . . . . . . . . . . . . 824

References . . . . . . . . . . . . . . . . . . . . . . . . . . . . . . . . . . . . . . . 824

\section{Introduction}

Sporophytes and gametophytes are the two alternating forms of the life cycle of plants, the former with somatic $(2 n)$ and the latter with haploid $(n)$ genomic constitution. Haploid and doubled-haploid $(\mathrm{DH})$ plants have gametophytic $(n)$ and sporophytic $(2 n)$ chromosome numbers. Furthermore, a haploid derived from a diploid is known as monoploid, while a haploid derived from a polyploid is a polyhaploid. Haploids occur spontaneously or can be induced by in vivo (inter- and intra-specific hybridization, centromere-mediated haploidization) or in vitro (culture of immature male or female gametophytes) methods (see Section 6). Natural sporophytic haploids in the higher plants were first spotted in Jimson weed (Datura stramonium L.) (Blakeslee et al., 1922), and later noted in several plant species including crops (Chase, 1947, 1949, 1969, 2005; Dunwell, 2010; Maluszynski et al., 2003; Nanda and Chase, 1966). However, doubled haploids were not highly relevant in plant breeding until researchers at the Department of Botany in the University of Delhi, India, reported a breakthrough in the production of haploids from anther culture in Datura (Guha and Maheshwari, 1964, 1966), and thereafter through the major discovery of induction of haploids through interspecific crosses followed by embryo culture as a promising method for obtaining haploids in barley (Hordeum vulgare L.) (Kasha and Kao, 1970). Their research revolutionized the use of $\mathrm{DH}$ technology in plant breeding worldwide. To date, DH technology has been used in cultivar development in selffertilizing species, or in inbred line development for their further use in producing hybrids of outcrossing species. Likewise, DH lines (DHLs) derived from hybrid offspring are used as recombinant inbred lines or RILs (Burr et al., 1988) in quantitative genetics research, or for discovering recessive, dominant and deleterious mutations (Castillo et al., 2001; Maluszynski et al., 1996; Szarejko and Forster, 2007 and references therein). DH are used in plant breeding or genetic research because they reach $100 \%$ homozygosity after one generation after the induction of haploids (instead of several generations of inbreeding through selfing), the small population size required to obtain a desired genotype (including mutants) from haploids, and last but not the least, the shortening of cultivar development and release.

Globally, DH technology has been effective for developing new cultivars. 'Maris Haplona' rapeseed and 'Mingo' barley were the earliest releases in Canada (Ho and Jones, 1980; Thompson, 1972), while most recent releases in wheat were 'BRS 328' in Brazil and 'Emerson' in Canada (Graf et al., 2013; Scheeren et al., 2014) or 'Kharoba' in Morocco (Elhaddoury et al., 2012). In excess of 300 DH-derived cultivars, with more than 100 cultivars each in barley and rice and above 50 rapeseed cultivars were reported (Chen, 1986; Daofen, 1986; de Buyser et al., 1987; DePauw et al., 2011; Dunwell, 2010; Elhaddoury et al., 2012; Forster and Thomas, 2005; Forster et al., 2007; Graf et al., 2003, 2013; Hu and Zeng, 1984; Humphreys et al., 2006, 2007, 2013;
Jain et al., 1996; Kang et al., 2011; Loo and Xu, 1986; Palmer et al., 2005; Pauk et al., 2009; Sadasivaiah et al., 2004; Sãulescu et al., 2012; Scheeren et al., 2014; Thomas et al., 2003; Tuvesson et al., 2007; Yang and Fu, 1989; Zhao et al., 1990; Zhu and Pan, 1990). DH-derived cultivars currently occupy significant acreage in some countries. For example, 25 wheat cultivars accounted for more than one third of the Canadian wheat acreage, with Lillian and AC Andrew being the most widely grown wheat cultivars in Canada (DePauw et al., 2011), or a DH-derived wheat cultivar Glossa grew in $16 \%$ of the total wheat area (300,000 ha) just in 5 years after its release in Romania (Sãulescu et al., 2012). The Peruvian highland barley farmers benefitted the most by growing DH-derived barley lines (Ya/LM94-PC27, B12/LM94-PC34), while the researchers in Peru saved 26\% research cost by adopting DH technology in barley breeding program (Gomez-Pando et al., 2009).

In vivo induction of $\mathrm{DH}$ is widely adopted method for inbred line development in maize (Zea mays L.) (Geiger and Gordillo, 2009; Prasanna et al., 2012). Unlike barley, maize, oat (Avena sativa L.), rice (Oryza sativa L.), rye (Secale cereale L.), and wheat among cereals (Forster et al., 2007; Jauhar et al., 2009; Germanà, 2011; Prasanna et al., 2012; Tadesse et al., 2012; Niu et al., 2014; http://www. agriculture.gov.sk.ca/agv1309-pg12), Brassica species among oilseeds (Xu et al., 2007) and potato (Solanum tuberosum L.) among tuber crops (Rokka, 2009), the DH technology in other crops including legumes (Croser et al., 2006) and root crops (Perera et al., 2014) has not reached to the stage leading to its use in plant breeding. In recent years a technology-driven approach such as centromere-mediated genome elimination procedure for the development of $\mathrm{DH}$, initially proposed in Arabidopsis (Comai, 2014; Ravi and Chan, 2010), have been undertaken in banana (Musa spp.), barley, Brachypodium, cassava (Manihot esculenta Crantz), Gossypium, Lotus japonicus, rice (Oryza sativa L.), soybean (Glycine max (L.) Merr.), sugarbeet (Beta vulgaris L.), switchgrass (Panicum virgatum L.), and tobacco (Nicotiana tabacum L.) (Tek et al., 2014). Although a few years have passed since the technique's development in Arabidopsis, there have been no published successes in other plant species.

Although the development of new cultivars is urgently needed to meet the demands of an increasing population and the challenges of a changing climate, cultivar development is a lengthy and timeconsuming process. New methods that enhance the efficiency of plant breeding are under investigation. Today, most crops have abundant genomic resources (Dwivedi et al., 2007), high throughput cost-effective phenotyping (Araus and Cairns, 2014; Cobb et al., 2013; Fiorani and Schurr, 2013), and genotyping tools (Thudi et al., 2012; Varshney et al., 2009). Likewise, the information on markers and genomic regions associated with agronomically beneficial traits (Dwivedi et al., 2007; Thudi et al., 2012; Varshney et al., 2009, 2013), and the genome sequences of many food crops (Bevan and Uauy, 2013; Hamilton and Buell, 2012) offer knowledge that has been used to breed new cultivars (Collard and 
Mackill, 2008; Dwivedi et al., 2007; Mba et al., 2012; Poland and Rife, 2012; Varshney et al., 2013, 2014). Above all, the scientific knowledge generated through DH technology has been enhanced in some crops such as barley, Brassica spp., maize, rice, triticale ( $x$ Triticosecale Wittm.) and wheat, and should be integrated with phenomics and genomics to accelerate cultivar development and economize plant breeding operations. This article deals with the induction and identification of haploids, factors influencing haploid induction, in vitro manipulation of gametic tissues for plant breeding, molecular basis of microspore embryogenesis, agrobacterium-mediated genetic transformation to support androgenesis, centromere-mediated genome elimination for induction of haploids, the genetics of haploid induction and breeding efficiency, trait fixation and unlocking new genetic variation from landraces, and the establishment of state of the art technology to support plant breeding programs for DH induction.

\section{Factors affecting gametophytic haploid production}

The genotype of the donor plant determines the efficiency of in vitro (Chen et al., 2011; Datta, 2005; Nitsch and Nitsch, 1969) or in vivo (Bitsch et al., 1998; Garcia-Llamas et al., 2004) haploid production. This response varies not only among species but also within a species, with few genotypes having great response while others being recalcitrant. For example, Brassica napus is more responsive to microspore embryogenesis compared to Brassica juncea, and winter genotypes are more responsive than the spring genotypes within B. napus (Chanana et al., 2005). Similarly, hexaploid wheat genotypes are more responsive compared to durum wheat genotypes (Almouslem et al., 1998; Amrani et al., 1993; Garcia-Llamas et al., 2004) and winter genotypes are more responsive than spring genotypes within hexaploid wheat (Sharma et al., 2005), while japonica types are more responsive to microspore embryogenesis than indica types in rice (Raina and Zapata, 1997; Shen et al., 1982). Genotype $\times$ bud size interactions and genotype $\times$ donor growth condition interactions also impact the efficiency of haploid production. Most of the plant species, with few exceptions, are recalcitrant for androgenesis, which is controlled by pollen-specific genes (Datta, 2005). The bulbosum technique for generating $\mathrm{DH}$, for example, in wheat has major limitation due to the presence of $K r$ inhibitor genes that express in the style of most of the wheat genotypes and inhibit Hordeum bulbosum pollen tube growth, whereas this limitation is not found when wheat is hybridized with maize (Laurie and Bennett, 1988). The same was observed for pearl millet (Laurie, 1989). Maize is insensitive to the action of $\mathrm{Kr} 1$ and $\mathrm{Kr} 2$ located on the long arms of wheat chromosomes 5B and 5A, respectively (Sitch et al., 1985). The physiological stage of the donor plants directly affects the efficiency of haploid induction. Plant age also influences androgenesis. The frequency of androgenesis is usually higher in anthers harvested at the beginning of the flowering period and declines with plant age (Bhojwani and Razdan, 1996). Pollen from old, sickly looking plants in B. napus and Brassica rapa yield more embryos than those from young and healthy plants (Burnett et al., 1992; Takahata et al., 1991), while anthers from primary tillers in most cereals -except rice (Dunwell, 1985)- are more responsive than those from lateral tillers.

The growth conditions of the donor plants significantly influence the physiological processes of plants, thereby affecting their microspore embryogenic ability (Prem et al., 2004). Donor plant temperature and light conditions influence haploid induction in wheat (Campbell et al., 1998; Jones and Petolino, 1987; Simmonds, 1989). Furthermore, regeneration response is usually high when the plants are grown under controlled environmental conditions (e.g., phytotron) vs. field grown plants (Datta, 2005).

The developmental stage of the explant used for culture initiation strongly influences the efficiency of haploid induction. For example, the stage of microspore development at the time of culture initiation is the most important factor influencing the microspore's totipotency during in vitro androgenesis. This occurs because microspores would only respond to embryo formation at a developmental stage when they are not committed to develop into pollen grains (Zaki and Dickinson, 1990). Microspores can be switched towards the sporophytic pathway within only a narrow period. For most species, the period around the first haploid mitosis (late uninucleate or early binucleate stage of development) has been shown to be the critical stage for microspore susceptibility to androgenic induction (Reynolds, 1997). In wheat, spikes containing anthers with pollen at the mid-late uninucleate stage of development are reported to be more effective (Liu et al., 2002). Microspore development in most crops is asynchronous and microspores at different developmental stages may be observed in a developing anther. Hence, selection of buds that have maximum proportion of embryogenic microspores is essential for efficient microspore embryo yield. The anther wall provides the nourishment in the development of isolated pollen of a number of species. Amino acids like glutamine and serine along with myoinositol could supplement the anther wall factor for isolated cultures (Maheshwari et al., 1980). Thickness of the anther wall also influences embryogenesis, with younger anthers more responsive. Anthers with thick wall may delay the diffusion of inducing factors to the anther locule, reducing their effect over inducible microspores. Thus, the culture of younger anthers would allow for younger microspores to grow up to the inducible stages while factors are entering the locule (Salas et al., 2012). Furthermore, bud size standardization is the critical step and is highly genotype-specific. For example, buds with 2.5 to $3.5 \mathrm{~mm}$ in size are reported to carry microspores in uninucleate stage in soybeans (Cardoso et al., 2007), while bud size of 2 to $2.5 \mathrm{~mm}$ in Brassicas contain maximum late uninucleate microspores (Gu et al., 2014). However, in anther culture, somatic cells of the anther wall that are diploid can enter dedifferentiation and divide, forming unwanted diploid calli or plantlets. This limitation can be overcome by isolated microspore culture methods as the anther wall tissues are removed thus preventing regeneration from the maternal sporophytic tissue (Murovec and Bohanec, 2012). Similarly, the efficiency of in vitro gynogenesis depends upon the stage of embryo sac and the success varies from culturing ovaries ranging from uninucleate to mature embryo sacs (Wang and Kuang, 1981; Zhou and Yang, 1981). Even though gynogenetic regenerants show higher genetic stability and a lower rate of albino plants compared to androgenetic ones, gynogenesis (female gametophyte) in comparison to androgenesis (male gametophyte) is less frequently used for the production of haploids. It is because of the presence of abundant male gametophytes contained in a single anther compared to the single gametophyte per ovule, and in part due to the ease with which anthers and pure populations of developing male gametophytes can be isolated.

Pretreatment of the explant before or after culture initiation was beneficial in improving the efficiency of DH production in many crops (Croser et al., 2005; Custers et al., 1994; Grewal et al., 2009; Kaur and Bhalla, 1998; Prem et al., 2005). Pre-treatment is needed to arrest the microspores in their gametophytic pathway. Their development is triggered through embryogenesis by promoting cell division followed by the formation of multicellular structures and finally, the embryo-like structures are released from the exine wall (Maraschin et al., 2005). The most widely used pre-treatment includes temperature, sucrose and nitrogen starvation and osmotic stress, which differ among species. Depending upon the species and genotypes, temperature stress can be applied by subjecting whole inflorescence or excised flower buds or excised anthers to low (barley, wheat, maize, rice, triticale, rye, pigeonpea, field pea) (Cai et al., 1988; Croser et al., 2005; Kaur and Bhalla, 1998) or high (Brassica species) (Custers et al., 1994; Prem et al., 2005) temperature for several hours or days. For example, cold-temperature pretreatment at $4{ }^{\circ} \mathrm{C}$ for five weeks has been reported to improve embryogenesis induction and green plant regeneration in otherwise recalcitrant durum wheat genotypes (Ayed et al., 2010). Prem et al. (2012) reported a novel system for efficient microspore embryogenesis induction in B. napus using continuous low temperature $\left(18{ }^{\circ} \mathrm{C}\right)$ treatment, favoring the embryogenesis pathway. It provides a convenient tool to analyze in situ the mechanisms underlying different 
developmental pathways during the microspore reprogramming, breaking or not the cellular symmetry, the establishment of polarity and the initiation of embryo patterning leading to development of mature embryos and plants. Mannitol pretreatment is also effective in improving the efficiency of anther-culture in durum wheat (Ayed et al., 2010; Labbani et al., 2007). A range of temperature pre-treatments to promote embryogenesis trigger different developmental stages in few crops. In rapeseed, early binucleate pollen grains require a heat shock treatment at $32{ }^{\circ} \mathrm{C}$ whereas extra heat shock treatment at $42{ }^{\circ} \mathrm{C}$ is needed for late binucleate pollen grains (Maraschin et al., 2005). A heat shock treatment is effective in triggering unicellular microspores while immature bicellular pollen grains need sucrose and nitrogen starvation for successful embryogenesis in tobacco [Nicotiana tabacum L.] (Touraev et al., 1997). Heat-shock proteins may play a role in inducing microspore embryogenesis. Seguí-Simarro et al. (2003) report a role for heat-shock proteins (HSP70 and HSP 90), while Zhao et al. (2003) indicated no role for HSPs (70 kDa and $19 \mathrm{kDa}$ ) in Brassica napus.

Various stress treatments such as cold temperature $\left(4^{\circ} \mathrm{C}\right)$ for 4 days, electric shock, centrifugation, and culturing anthers in high-osmotic pressure $(563 \mathrm{~m} \mathrm{~mol})$ liquid medium were exploited to generate DHs in chickpea (Grewal et al., 2009), of which electroporation of anthers was effective to enhance root formation and hence provided an efficient DH protocol for chickpea.

The constituents of the basal medium and combinations of growth regulators play an important role in haploid induction. The reprogramming of explant from gametophytic to sporophytic pathway, for example, depends upon the type and concentration of carbohydrates and plant growth regulators (Murovec and Bohanec, 2012). The requirement of culture medium is species and genotype specific. Hence, there is no single culture medium that would be suitable for haploid induction systems in various crops. Different types of culture media are suitable for a range of crops, and most media such as MS, N6, modified MS media, and B5 (Chu, 1978; Gamborg et al., 1968; Murashige and Skoog, 1962; Nitsch and Nitsch, 1969) are specific for a few or even one genotype within a species. Research has been carried out to compare the efficiency of different media for haploid induction in different crops (Gioi and Tuan, 2002; Khatun et al., 2012). Grauda et al. (2010) noted an increased DH production efficiency in wheat through the utilization of androgenic microspore culture induction medium with copper, which has been effective in reducing albino plants and increasing green plant regenerants. These effects are related to improved survival of microspores during the different tissue culture stages and with the synchronization of the first microspore symmetric division (Jacquard et al., 2009). The source and amount of total nitrogen as well as combination of a cytokinin and auxin treatments determine the regeneration pathway either directly via embryogenesis or via callus formation (Ball et al., 1993; Liang et al., 1987). The type and concentration of auxins seem to determine the pathway of microspore development (Ball et al., 1993), with 2,4-D inducing callus formation, whereas indole 3-acetic acid (IAA) and naphthalene acetic acid (NAA) promoting direct embryogenesis (Liang et al., 1987). Pretreatment of wheat spikes with $0.4 \mathrm{M}$ mannitol at $4{ }^{\circ} \mathrm{C}$ followed by embryoid induction and regeneration in a medium fortified with ascorbic acid produces highest number of green plants (Santra et al., 2012). Besides basal medium and growth regulators, the beneficial role of growth additives such as glutamine, casein, proline, biotin, inositol, coconut water, silver nitrate and activated charcoal in the medium for enhancing the embryogenic response has also been reported in different crops (Kaur and Bhalla, 1998; Prem et al., 2008).

Culture incubation conditions have profound effects on the induction and development of haploid embryos. External stimulus such as pretreatment is needed to switch gametic cell development from the gametophytic to the sporophytic pathway in many species. Besides pre-treatment, light intensity and light/dark culture conditions also plays an important role in haploid regeneration. For anther and microspore culture as well as for embryo culture in wheat $\times$ maize and wheat $\times$ Imperata cylindrica system, initial incubation of cultures in dark has found to be the best for haploid regeneration (Chaudhary et al., 2005). In addition, timing of embryo culture and crossing timing is important in wheat $\times$ pearl millet (Inagaki and Bohorova, 1995). Further, the effect of temperature on the frequency of barley haploids has been noticed (Pickering, 1984; Pickering and Morgan, 1985).

There is a relationship between microspore embryogenesis and chemical treatment. For example, using a chemical inducer formulation consisting of $0.1 \mathrm{~g} \mathrm{~L}^{-1}$ of 2-hydroxinicotinic acid, $10^{-6} \mathrm{~mol} \mathrm{~L}^{-1} 2,4-$ dichlorophenoxyacetic acid, and $10^{-6} \mathrm{~mol} \mathrm{~L}^{-1}$ 6-benzylaminopurines, Liu et al. (2002) generated a large number of microspore-derived green plants from a wide spectrum of wheat germplasms under optimum culture conditions, thus suggesting that a method based on chemical formulation is highly efficient in generating doubled haploid green plants from wheat microspores. Likewise, the blocking of histone deacetylase (HDAC) activity with trichostatin A (TSA) in cultured male gametophytes led to a significant increase of pollen switching to embryogenic growth in oilseed rape (Li et al., 2014), thereby confirming that HDAC regulates haploid embryogenesis.

\section{In vitro manipulation of gametic tissues for plant breeding}

\subsection{Gametoclonal variation}

The variation observed among plants regenerated from cultured gametic cells is termed gametoclonal variation (Evans et al., 1984), for example, variation for several agronomic traits was noted in wheat (but not in barley) using bulbosum method of DH production (Snape et al., 1988). Variation from gynogenically derived tef (Eragrostis teff (Zuccagni)), an important cereal crop of Ethiopia, was found for plant height, panicle length, culm thickness, seed size, and maturity (Gugsa and Loerz, 2013; Gugsa et al., 2006). Likewise, several DH regenerants obtained after anther culture (or microspores) showed large variation for improved agronomic characteristics in rice (Ying et al., 1996; Yoshida et al., 1998), while dihaploid plants in potato originating through gametoclonal variation during androgenic dihaploidization were genetically most distinct from their tetraploid anther-derived sibs as well as anther donor (Sarkar et al., 2010). Biotechnological and molecular analysis indicated a high degree of genetic stability of gametoclones (Datta, 2005). Hence, anther culture may, to some extent, modify the performance of microspore-derived plants, without dramatically affecting their utilization in plant breeding and genetic engineering programs.

\subsection{Gametosomatic hybridization}

Protoplast fusion is triggered following chemical or electric treatment. Gametosomatic hybridization refers to the fusion between male gametic (microspore tetrad or young-stage pollen) and somatic cell protoplasts. Thus, both nuclear and organellar genomes can be combined to generate novel nuclear-organellar genomic combinations. The fusion product is termed a heterokaryons (Davey et al., 1996). Earlier attempts to produce gametosomatic hybridization by the fusion between male-gametophyte protoplast and somatic protoplast were successful (Choi et al., 1992; Lee and Power, 1988a,b). Gametosomatic hybridization has been reported in genus Nicotiana and Petunia (Choi et al., 1992; Desprez et al., 1995; Giddings and Rees, 1992; Lee and Power, 1988a,b; Pental et al., 1988). Isolation of ovules from the ovary is a very cumbersome procedure, with risk of damage to ovary and contamination from somatic tissue. Using a procedure developed for isolating female germ unit (FGU) from ovules of Petunia (Sangthong et al., 2009a), Sangthong et al. (2009b) successfully reported gametosomatic hybridization by using female gametophyte (egg cell) as the gametic-haploid partner instead of male gametophyte in Petunia hybrida. More recently, Skálová et al. (2012) reported isolation of haploid and mixoploid protoplasts in cucumber (Cucumis sativus $\mathrm{L}$; $2 \mathrm{x} / 4 \mathrm{x} ; 2 \mathrm{x}=14$ ). They further 
improved the isolation and cultivation of the cucumber and muskmelon (C. melo $\mathrm{L} ; 2 \mathrm{x}=24$ ) haploid protoplasts from young-stage pollen grains, and reported for the first time gametosomatic hybridization between mixoploid cucumber protoplasts and pollen muskmelon protoplasts.

\subsection{Haploid protoplast}

Protoplast fusion facilitates the transfer of genes from related but sexually incompatible species to another species without genetic transformation. The genus Brassica has been the most extensively studied for protoplast fusion for either resynthesizing the particular species or transferring agronomically beneficial traits, e.g., Ogura and Nigra cytoplasm from Brassica oleracea to B. campestris (Christey et al., 1991; Heath and Earle, 1996); or 'Anand' cytoplasm from B. rapa to B. olerecea (Cardi and Earle, 1997); cold tolerant Ogura male sterile cytoplasm into cabbage (B. oleracea var. capitata) (Sigareva and Earle, 1997); resynthesizing B. napus (Sundberg et al., 1987) and B. carinata (Narasimhulu et al., 1992); and for improving resistance to bacterial soft rot (Erwinia carotovora subsp. carotovora) (Ren et al., 2000). Protoplast fusion using somatic tissues has also been successful in cotton, facilitating gene transfer from its wild relatives (Sun et al., 2004, 2005, 2006).

\section{Molecular basis of microspore embryogenesis}

Microspore embryogenesis involves reprogramming of the pollen immature cell towards embryogenesis. The use of functional genomic tools has allowed the identification of genes associated with microspore embryogenesis (ME) in barley and rapeseed (Joosen et al., 2007; Malik et al., 2007; Maraschin et al., 2006; Muñoz-Amatriaín et al., 2006, 2009; Seguí-Simarro and Nuez, 2008; Tsuwamoto et al., 2007). There are 14 genes (TaTPD1-like, TAA1b, GSTF2, GSTA2, TaNF-YA, TaAGL14, TaFLA26, CHI3, XIP-R, Tad1, WALI6, TaEXPB4, TaAGP31-LIKE, and TaME1) associated with early, middle, and late stages of microspore embryogenesis in wheat. The comparison of gene expression among wheat cultivars differing in response to anther culture revealed that the profile of genes activated before exine rupture is shifted to earlier stages in the low-responding cultivar. This collection of genes thus constitutes a valuable resource to study intra-embryo communication, early pattern formation, cell wall modification and embryo differentiation in wheat (Sánchez-Díaz et al., 2013). Moreover, 13 of these genes were also associated with ME in triticale lines, from highly embryogenic to recalcitrant. In a highly embryogenic line DH28, all genes were up-regulated during the first 8 days of in vitro culture $(\mathrm{dc})$. In the less embryogenic line DH31, TAA1b, GSTA2 and TaEXPG4 were already induced on $4 \mathrm{dc}$, while in DH25, ME initiated quite efficiently but soon inhibited, which coincided with the lack of gene expression (TaEXPB4, TaME1) or down-regulation (Tad1, XIP-R1, TaAGL14, TaNF-YA, SERK2, SERK1) on $8 \mathrm{dc}$. In the recalcitrant DH50, the majority of the genes were expressed at a lower level or not at all, indicating disturbances in microspore embryogenesis (Żur et al., 2014). Further research should characterize the function of specific genes controlling microspore-derived embryo development.

Tissues from isolated microspores undergoing induction of embryogenesis experience dramatic changes in developmental fate. Using B. napus microspores covering all the stages of microspore embryogenesis, high pressure freezing and freeze substitution (HPF/FS) fixation technology (Gilkey and Staehelin, 1986), and electron microscopy, Corral-Martínez et al. (2013) showed massive autophagy exclusively in the embryogenic microspores, but not in other microspores-derived structures also present in the cultures. Autophagy is a process that removes and recycles cellular debris including non-proteinaceous material, large particles such as organelles, and even entire cytoplasmic regions in response to stress or during developmental transition (Liu and Bassham, 2012). A significant part of the autophagosomal cargo was not recycled, but transported out of the cell producing numerous deposits of extracytoplasmic fibrillar and membranous material (Corral-
Martínez et al., 2013). The commitment of microspores to embryogenesis is associated with both massive autophagy and excretion of the removed material.

Barley is an excellent model plant system for studying pollen embryogenesis. Daghma et al. (2012) developed a cell culture system in which immature barley pollen are cultured as a monolayer trapped between the bottom glass-cover slip of a live-cell chamber and a diaphanous PTFE membrane within a liquid medium over a period of up to 28 days. This method allows researchers to capture images automatically every $3 \mathrm{~min}$, beginning at the unicellular pollen stage up until the development of multicellular, embryogenic structure. This cell culture system facilitates the elucidation of ultrastructural features and molecular processes associated with pollen embryogenesis. Using time-lapse imaging on transgenic barley expressing nuclear localized Green Fluorescent Protein, Daghma et al. (2014) investigated the cellular dynamics during the onset of pollen embryogenesis and identified nine distinct embryogenic and non-embryogenic types of pollen response to the culture conditions. Cell proliferation in embryogenic pollen normally started via a first symmetric mitosis and only rarely via asymmetric pollen mitosis, while the fusion of cell nuclei was the only mechanism of genome duplication observed under cultured conditions. This novel technique may also assist elucidating the still unknown molecular triggers of pollen embryogenesis through observation of fluorescenttagged subcellular structures of candidate proteins essentially involved in pollen embryogenesis.

\section{Identifying putative haploids (focusing on recent advances in maize)}

A key issue for the commercialization of DH technology is the development of an efficient system for identification of putative haploids. This becomes crucial when using in vivo DH technology for induction and identification of haploids from hybrid seeds. Several methods are now available to identify haploids from hybrids as discussed herewith.

\subsection{Plant morphology and stomatal chloroplast count}

This is the indirect method of selection wherein haploids and DH are identified by comparing plant morphology such as plant height, leaf size, flower morphology, plant vigor and fertility, number of chloroplasts and their size in stomatal guard cells. Haploid plants show reduced plant vigor with degenerated flowers or anthers and are mostly sterile or show greatly reduced fertility, whereas diploid individuals resemble the donor plant and are often characterized by normal flower and pollen development (De Laat et al., 1987). These methods are not reliable, however, particularly if the ploidy differences are small and are often subject to environmental effects. A dominant marker gene $R 1-n j$, which leads to a colored (purple pigmentation) embryo in the hybrid seed and uncolored embryo in haploid seed, is the most commonly used system to identify putative haploids in maize (Greenblatt and Bock, 1967; Nanda and Chase, 1966). Nevertheless, the female parent (in the genetic background carrying the 'inhibitor' gene, C1-1, that suppresses anthocyanin pigmentation of the embryo in $C$ seeds), the genotype of the donor plant or those with purple or red pericarp color (Chaikam et al., 2015), and environmental conditions influence the expression of R1-nj (Chaikam and Prasanna, 2012; Kebede et al., 2011). Very recently, two gene-specific markers-8 bp C1-I InDel and C1-I SNP- were found to predict with high accuracy the presence of anthocyanin color inhibition (Chaikam et al., 2015). They will facilitate high-throughput and cost-effective screening of a large pool of maize germplasm for the presence of the dominant color inhibitor.

Distinguishing haploid from hybrid seed by manual selection based on marker gene R1-nj is labor intensive, time consuming, and not amenable to automation (Melchinger et al., 2013). In addition to the anthocyanin marker, maize seedling vigor is used as a marker for eliminating false haploids and selecting putative haploids (low vigor with smaller 
radicles and coleoptiles) prior to performing chromosomal duplication (Battistelli et al., 2013). Research in barley, wheat and rye suggest that length of stomata guard cells in the leaf correlate well with ploidy level and DNA content. This trait could be used to differentiate haploids and DHs from outcrossing plants (Borrino and Powell, 1988; Sood et al., 2003). A recent study in maize revealed that mean stomata length of haploid and DH plants at early stage (through leaf 1 to leaf 8 stage) is significantly smaller than that of the diploid controls (outcrossing seeds), thus indicating that stomata length together with anthocyanin color could be used to detect true haploids and DHs from control plants derived from outcrossing seeds (Choe et al., 2012).

\subsection{Chromosome counting}

This is one of the direct and precise methods for ploidy level determination. Haploids and DH plants can be identified by chromosome counting during mitotic or meiotic cell division. Chromosome counting during mitotic division is easy and fast, and can be done by using root tips or other meristamatic tissues (Maluszynska, 2003). Determination of ploidy by counting mitotic chromosomes is, however, time consuming and difficult especially in crops with small chromosomes such as B. napus (Weber et al., 2004).

\subsection{Flow cytometry}

Flow cytometry using DNA selective flourochromes has been considered to be the fast and reliable method for the measurement of nuclear DNA content (Doležel et al., 2007; Ochatt, 2008). Flow cytometry enables the measurement of ploidy level in an early developmental stage of plantlets emerging from microspore culture. Hence it provides a rapid and simple option for large-scale ploidy determination in early phases. Flow cytometry also allows the detection of mixoploid (plants with unequal number of chromosome sets in adjacent cells or tissues) regenerants. Although flow cytometry is an efficient technique with high degree of accuracy, the preparation of high quality plant samples for ploidy analysis is the hurdle that accounts for its low utilization in plant breeding.

\subsection{Biochemical marker}

Melchinger et al. (2013) reported an alternative method for discrimination of haploid from diploid seeds based on differences in oil content, when used high oil inducers as source of pollinator for induction of haploids. Using this method, they found an acceptable error rates across different germplasm in maize. In this method, the seeds harvested from the maternal parent are classified as haploid or hybrid depending on whether their oil content is below or above a predefined threshold $(t)$, which is determined based on differences in oil content between maternal and haploid inducer parents. The success of this method depend, however, on the haploid induction rate of the inducer and the variation present in the donor parent genetics, the difference in the mean oil content of haploid and hybrid seeds, the phenotypic variance associated with differences in oil content between two seed factions (haploids and hybrids), and the choice of an appropriate threshold $t$ for discriminating putative haploid from hybrid seeds. When further tested the utility of this assay on a range of diverse maize germplasm (single cross, synthetics and landraces) pollinated by a high oil inducer (UH600), Melchinger et al. (2014) found that the average difference (1.79\%) between the mean oil content of haploid and hybrid seeds was more than twice the standard deviation within each fraction. Thus, sorting haploid and hybrid seeds based on oil content smaller or greater than a priori chosen threshold $t$ is more reliable than based on the $R 1-n j$ embryo marker. However, it is important to note that use of high oil inducer is mandatory to achieve reliable sorting of haploid and hybrid seeds on the basis of their oil content. Further work on automation using a high-throughput system based on nuclear magnetic resonance is in progress for routine application of this assay on identification of haploid from hybrid seeds in maize breeding programs (Melchinger et al., 2013).

\subsection{Molecular markers}

Simple sequence repeats (SSR) have been used to identify spontaneous doubled haploids in many plants (Aulinger et al., 2003; Höfer et al., 2002; Muranty et al., 2002; Tang et al., 2006). A specific microsatellite primer pair Mim-top6B for Mimulus species was used successfully to identify DH of Mimulus aurantiacus (Murovec et al., 2007). This codominant locus, which shows a cross-species applicability, allows selecting donor plants and identifying regenerants at a very early stage in the in vitro tissue culture phase, thus resulting in labor and cost savings. SSR have also been found effective in identifying doubled haploids originating through androgenesis in coconut (Cocos nucifera L.) (Perera et al., 2008) or through gynogenesis in cucumber (Cucumis sativus L.) (Diao et al., 2009) and melon (Cucumis melo L.) (Malik et al., 2011). Enzymatic mismatch cleavage, which has been used in TILLING, is another low-cost, rapid screening system for DH production without needing specialized equipment (Hofinger et al., 2013). This approach also seems to be more efficient than SSR-based screening in plants for detecting heterozygosity and selecting DHs that are genetically distinct from each other.

\section{Conventional methods to induce doubled haploids}

The in vitro procedure using androgenesis (anther or microspore culture) and gynogenesis (unfertilized egg cell) has been used to produce DH. Androgenesis refers to culturing immature anther or microspores from the immature pollen grain in artificial media to isolate haploid cells that are then chromosome doubled using colchicine to develop DH. It is beyond the scope of this review to provide a depth discussion on $\mathrm{DH}$ production using this technology because there are excellent articles on this subject elsewhere (Croser et al., 2006; Dunwell, 2010; Forster et al., 2007; Germanà, 2011). It should be noted, however, that haploid production by in vitro culture is a highly technical procedure; labor-intensive, time-consuming and costly; and more importantly, species- and genotype-dependent. Other constraints associated with use of this technology are the low rate of embryogenesis and regeneration, high frequency of albinism, segregation distortion, and the low frequency of chromosome doubling to obtain DH (Dunwell, 2010). This technology has been standardized and routinely used for production of DH in barley, Brassica, oat, rice, and triticale (Dunwell, 2010; Forster et al., 2007; Germanà, 2011).

The in vivo method (interspecific hybridization) for haploid induction was first used in barley, and termed the bulbosum method (Kasha and Kao, 1970). The underlying mechanism is uniparental chromosome elimination during early development stages of a hybrid embryo leading to the formation of haploid embryo. Other species in genus Hordeum have also been reported to induce haploids in crosses with $\mathrm{H}$. vulgare (Houben et al., 2011; Jorgensen and von Bothmer, 1988). Interspecific hybridization has also been used to isolate DH in tobacco (Burk et al., 1979) and potato (Caligari et al., 1988; Peloquin et al., 1996), while inter-generic or more distant crosses such as Cichorium intybus $\times$ Cicerbita alpina (Doré et al., 1996), pear $\times$ apple (Inoue et al., 2004), B. napus $\times$ Orychophragmus violaceus (Cheng et al., 2002), B. rapa $\times$ Isatis indigotica (Tu et al., 2009), Avena sativa $\times$ Z. mays (Kynast et al., 2012), Triticum turgidum $\times Z$. mays (Almouslem et al., 1998), wheat $\times$ pearl millet (Pennisetum glaucum (L.) R.Br) (Laurie, 1989), and Triticum aestivum $\times$ Triticeae species (H. vulgare and $H$. bulbosum) or T. aestivum crossed with more distantly related species (Liu et al., 2014), have been used to isolate $\mathrm{DH}$. Wheat-maize or wheat-barley hybridizations are preferred for the production of DH lines in wheat (Jauhar et al., 2009; Polgári et al., 2014), with wheat-barley hybridization having a high frequency (76\%) of wheat maternal haploids and providing a useful resource 
to study the mechanism of uniparental chromosome elimination in cereals.

In vivo maternal haploid induction is the most frequently used method for production of haploids in maize. The genomes of maternal haploids originate exclusively from the seed parent and the haploid induction is caused by pollen parent. Over the years, this system has improved considerably in maize, largely due to discovery of high inducer stocks (WS14, MHI, CAUHOI, and RWS), which when crossed with other lines, release up to $10 \%$ haploids (Wu et al., 2014a and references therein). Recently the use of inducer lines in maize, such as PHI\# 1, 2, 3 and 4, led to producing 11 to $16 \%$ haploids; although the response is genotype-specific (http://www.agron.missouri.edu/mnl/84/PDF/15rotarenco.pdf).

Colchicine is most often used chemical agent for doubling the chromosomes, achieved by in vivo treatment of seedlings. It is an antimicrotubule drug, which inhibits microtubule polymerization by binding to tubulin. Despite its effectiveness in artificial chromosome doubling and its suitability for large-scale DH-line production, in many cases its high cost, toxicity and labor intensiveness present major challenge for DH line production. In vitro application of colchicine is an alternative for doubled haploid production using microspore culture. Using this method of colchicine application, Würschum et al. (2012) showed a pronounce increase in the proportion of doubled haploid triticale plants, thus a promising alternative to the in vivo approach. The antimicrotubule herbicides such as amiprophos methyl, oryzalin, and pronamide are effective in doubling chromosome sets of maize; being less toxic than that of colchicine (Häntzschel and Weber, 2010). Nitrous oxide gas has also been found effective in doubling the chromosome numbers in maize (Kato, 2002). Spontaneous occurrence of DHs, although in low frequency, has been reported in maize (Geiger and Schönleben, 2011; Geiger et al., 2006), which should be further investigated to identify lines producing natural DHs in high frequency to skip chromosome doubling by colchicine.

Wu et al. (2014b) reported occurrence of an early doubled haploid (EDH) that they generated directly by in vivo haploid induction in maize, which they further confirmed as homozygous diploids via flow cytometry and SSR fingerprinting. The spontaneous doubling in EDH occurred during embryo development at haploid induction. The EDH lines exhibited complete fertility, which could be used in DH breeding as a new breeding strategy in maize. However, before the EDH system is put to practical use in maize breeding, several issues need to be investigated, e.g., increasing the rate of spontaneous DH production, discovering inducers that produce sufficient EDH, elucidating the mechanisms underlying haploid inducing and doubling, or determining the process of spontaneous haploid doubling $(\mathrm{Wu}$ et al., 2014b).

Irradiated pollen has been used in the production of maternal haploids in some fruits, vegetables, and ornamental plants (Murovec and Bohanec, 2012). The embryo development in this method is stimulated by pollen (irradiated) germination on the stigma and growth of the pollen tube within the style, although irradiated pollen is unable to fertilize the egg cell. The use of this technique has been, however, limited due to labor intensive, low frequency and requirement of in vitro embryo rescue.

Zhang et al. (2011) used meiotic restitution genes (Zhang et al., 2007) to synthesize DH (SynDH) in wheat. An inducer line with gene(s) for meiotic restitution and an alien species that can be crossed without embryo rescue are needed. It is a three-step procedure involving hybridization to induce recombination, interspecific hybridization to extract haploids, and spontaneous chromosome doubling by selfing the interspecific $F_{1}$, with no special equipment or treatments involved in $\mathrm{DH}$ production.

\section{Agrobacterium-mediated genetic transformation to androgenesis}

Using a novel genetic transformation method based on infection of androgenic pollen cultures with Agrobacterium tumefancies, Kumlehn et al. (2006) produced primary transgenic $\left(\mathrm{T}_{0}\right)$ plants in barley carrying a single copy of the sequence integrated, of which about $60 \%$ of the plants set seed, indicating spontaneous genome doubling, which opens up the opportunity for production of doubled haploid $\mathrm{T}_{1}$ seeds instantly homozygous for the transgene. More importantly, this method has great potential for application in other plant species as androgenesis and Agrobacterium-mediated transformation are feasible in many angiosperms.

Haploid embryos can be used for engineering of DH homozygous for the transgene. A drought tolerant and stable transgenic haploid wheat plants using the barley gene HVA1 was bred using explants from anther culture-derived haploid embryos of the commercial wheat cultivar CPAN1676 through Agrobatcerium-mediated genetic transformation (Chauhan and Khurana, 2011). The transgenic plants were chromosome doubled with colchicine to produce DHs that did not show transgene silencing until the $\mathrm{T}_{4}$ generation. Furthermore, these $\mathrm{DH}$ plants had faster seed germination and seedling establishment and show better drought tolerance that non-transgenic DH plants. DH technology can be also useful for fixing a transgene while simultaneously removing unwanted selectable marker gene (Kapusi et al., 2013). This approach, which saves time and resources, may be also useful for both for developing stable true breeding transgenic-derived DHs with gene of interest, and for functional genomics studies.

Unicellular tobacco microspores were used to produce transgenic plants (Touraev et al., 1997), The developers of this protocol -known as male-germ line transformation (MAGELITR)- indicated that it is fast, regeneration-independent, and does not produce either chimerism or somaclonal variation. Androgenic microspores of wheat were generated either through electroporation or by and co-cultivation with Agrobacterium tumefaciens when using a double-cassette vector (RS $128 / \mathrm{Xyl}$ ) containing 1,4- $\beta$-xylanase or an endochitinase gene derived from Trichoderma harzianum (Brew-Appiah et al., 2013). There were 19 fertile plants (from five genotypes) with transgenes in the $T_{0}$ transformants and stable performance in homozygous $\mathrm{T}_{1: 2} \mathrm{DH}$ offspring. This research resulted in the incorporation of single or several transgenes in homozygous form at 8 months in spring and at 16 months in winter wheat cultivars. Microspore-derived embryos were also used for genetic engineering in oilseed rape (Ferrie and Möllers, 2011 and references therein). Moreover, DH methodology was used in transgenic oilseed rape for generating homozygous lines with trait of interest, e.g., host plant resistance to pests (Åhman et al., 2006; Reiss et al., 2009). These results show that this method may accelerate plant breeding because homozygous transgenic lines are bred in one generation.

The use of short peptide nanocarriers as delivery method facilitated microspore transformation, which opens new options for plant breeding (Eudes et al., 2014). For example, haploid transformed plants of triticale microspores were regenerated after genetic engineering microspores using coupling of cell-penetrating peptides with plasmid DNA (Chugh et al., 2009). An advantage of this DNA delivery into microspores lies on the lack of requirement for a selectable marker gene; an end-point PCR-based method suffices for rapid identification of a microspore-derived transformed plant.

Transcription activator-like effector nucleases (TALENs) generate site-directed genetic modification in a range of cells and organisms, and is widely used for targeted genome editing (Chen and Gao, 2013). Using gfp-specific TALEN pairs expressed via Agrobacterium-mediated transformation in embryonic pollen of transgenic barley harboring a functional copy of gfp, Gurushidze et al. (2014) demonstrated that customizable designer nucleases are expressed and function in haploid cells, which in turn can be instantly regenerated into non-chimeric homozygous mutants.

Microspore engineering and newer breeding techniques such as TALENs are providing options to produce DH lines with desired trait(s) in one season instead of the two seasons used in crossbreeding or for elucidating gene function. 


\section{Centromere-mediated genetic engineering to haploid induction}

As discussed above, haploid plants can be induced through the regeneration of plants from haploid (gametic) tissues, through the destruction of a single parent's genome (for example, through irradiation of pollen) or through the selective loss of one parent's chromosomes during early embryogenesis (Sanei et al., 2011) (which can be induced by interspecific hybridization or by "haploid inducing" variants). All of the above techniques work for some species, or cultivars, but not for others. For many species, none of these approaches work. More recently, a transgenic methodology for the induction of uniparental inheritance was developed in Arabidopsis. The effects of this technology resemble that induced by interspecific hybridization or by haploid-inducers. The chromosomes of the transgenic parent are selectively lost during early embryogenesis. This transgenic technology involves the manipulation of the protein CenH3, which is a histone 3 variant that is specifically localized to centromeres, replacing $\mathrm{H} 3$ in centromeric nucleosomes. In fact, it has become clear that the position of $\mathrm{CenH} 3$ defines the position of the centromere. The centromere is defined epigenetically in most organisms (Allshire and Karpen, 2008). Experimentally induced re-localization of CenH3 to alternate chromosomal loci results in the formation of functional centromeres at the new site, and, conversely, formation of new functional centromeres ("neocentromeres") is accompanied by the migration of CenH3 localization to the site of the new centromere (Burrack and Berman, 2012). The selective reloading of CenH3 to centromeric sites after DNA replication is a critical step in chromosome biology. The failure to maintain CenH3 status would result in a chromosome that cannot segregate, while ectopic loading would result in a dicentric, which can induce a chromosome break at division.

Ravi and Chan (2010) discovered a haploid-inducing variant of $\mathrm{CenH} 3$ during their studies of $\mathrm{CenH} 3$ function. While non-centromeric histones are highly conserved, the sequence of centromeric H3 (also termed (enpA), in contrast, varies widely even between closely related species (Cooper and Henikoff, 2004). This adaptive evolution, shared with many genes involved in reproduction (Swanson and Vacquier, 2002), has been the subject of much speculation (Henikoff et al., 2001). Like all histones, the structure of CenH3 can be divided into a histone fold domain (which interacts with DNA and other histones), and the N-terminal tail, which displays most of the extreme diversity observed even within angiosperm CenH's (Cooper and Henikoff, 2004). The N-terminal tail, which is loosely structured, extends into the cellular space surrounding the nucleosome and is often decorated with tags, such as acetyl, phosphate, or methyl groups, which affect chromatin function.

In their research into CenH3 function, Ravi and Chan (2010) created a chimeric $\mathrm{H} 3.3 / \mathrm{CenH} 3$ protein in which the $\mathrm{N}$-terminal tail of a conventional Arabidopsis $\mathrm{H} 3$ replaced the CenH3 tail. In order to visualize localization of this protein, GFP (Green Fluorescent Protein) was added to the N-terminus. The resulting protein, termed GFPtailswap, did indeed localize to centromeres and was able to complement the lethal phenotype of a cenH3 null mutant, indicating that the CenH3's N-terminal tail, which is completely unrelated to H3's tail in sequence, is not required for CenH3's mitotic function (Ravi et al., 2010). The transgenic cenH3-/-GFPtailswap plant was partially sterile, successfully selfpollinating at about $1 \%$ of the normal rate (Ravi et al., 2011). This effect is largely due to its male sterility, but there is also mild female sterility. On outcrossing the plants frequently produce haploids, retaining the chromosomes derived from the wild-type parent. When employed as a female, GFPtailswap plants produce 25 to $50 \%$ paternal haploid plants (Ravi and Chan, 2010). These paternal haploids are (as expected) nearly sterile, but do regularly produce a few DH offspring. Aneuploids, carrying one or more additional maternal chromosomes, are also produced in GFPtailswap $\times$ wild-type crosses at a high frequency (about 25\%). These aneuploid plants usually carry conventional diploid genomes (wildtype and GFPtailswap-derived) with an additional GFPtailswap-derived chromosome.
The GFPtailswap cenH3-/- line of Arabidopsis is a highly efficient haploid inducer. After outcrossing, a large fraction of its progeny will carry only the chromosomes of the wild-type parent. Given the transgenic nature of this alteration, this technology might be translated directly into crops. To the best of our knowledge, the efficacy of this technology has not been, however, demonstrated in any other species. The haploid inducer effect, in Arabidopsis, requires both the GFPtailswap transgene and the absence of wild-type $\mathrm{CenH} 3$ function. Thus translation into a crop will require the isolation or generation of a cenH3 null allele, in combination with expression of the (species-specific) GFPtailswap construct. Fortunately cen $\mathrm{H} 3+/-$ heterozygotes are fertile, and the null allele is transmissible, and therefore these two requirements can be achieved independently.

Although the GFPtailswap technology is transgenic, plants produced via this technology carry only the chromosomes derived only from the non-transgenic parent. Thus where regulatory status is determined by the transgenic nature of the plant itself, rather than the possibly transgenic nature of the plant's ancestors, DH derived from GFPtailswap lines should be free from regulatory burden.

The mechanism through which GFPtailswap exerts its serendipitous effect remains obscure. A likely scenario, testable but presently unsupported by published data, is given in Fig. 1. In this model the GFPtailswap-labeled chromosomes present in the zygote often though not always- fail compete with wild-type $(\mathrm{Cenh} 3+)$ centromeres for one or more factors required for assembly of a functional kinetochore. As a result, the HI-derived chromosomes may be lost from the nucleus entirely, or fail to segregate but remain in one daughter cell, where they

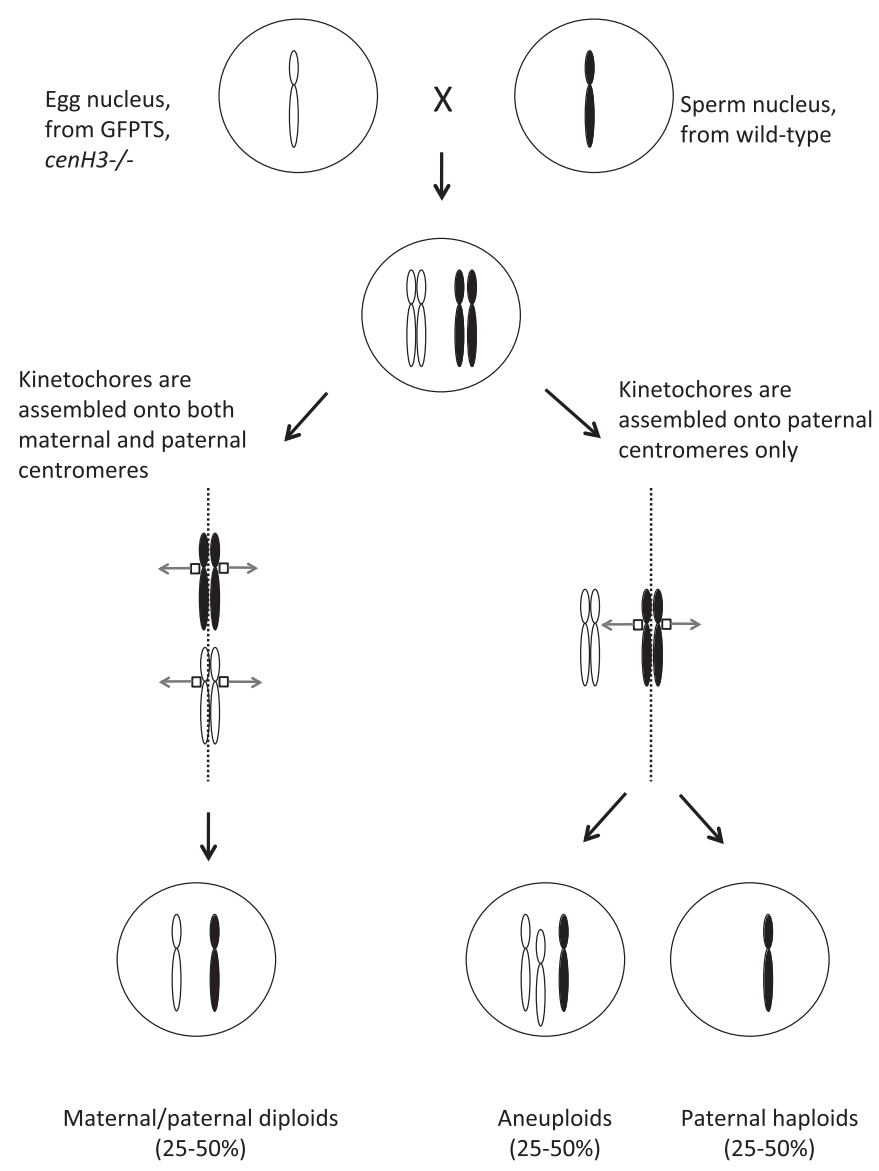

Fig. 1. Centromere-mediated genome elimination leads to haploid induction (In this model, chromosomes from the GFP-tailswap parent often fail to compete with centromeres from the wild-type parent for components required to build a functional kinetochore. This results in the complete loss of the GFP-tailswap-derived chromosomes in approximately $40 \%$ of progeny). 
may be or not be reloaded with the wild-type CenH3 to facilitate segregation in later cell divisions.

The importance of this specific defect in CenH3 is also unclear: GFPcenH3 (no tailswap) can also act as a haploid inducer (Ravi and Chan, 2010), though at low efficiency. Not all transformed lines of Arabidopsis carrying the GFPtailswap construct are efficient haploid inducers. The most effective line carries four copies of the construct, at two loci. Addition of a variety of other proteins to the N-terminus of tailswapCenH3 can variously destroy its function or have no effect, and there is no particular correlation of effect with the size of the Nterminal addition. It has recently been demonstrated (Maheshwari et al., 2015) that natural (interspecific) variants of CenH3 can produce plants that are self-fertile but haploid-inducing on outcrossing to plants expressing wild-type (intraspecific) CenH3. Maheshwari et al. transgenically introduced the $\mathrm{CenH} 3$ gene from a variety of plant species into a cenH3-/- mutant of Arabidopsis. They found that $\mathrm{CenH}$ from species as distant as Zea mays complemented the mutant's viability defect and produced fertile plants (on self pollination) that, like GFPtailswap lines, acted as haploid inducers on outcrossing, preserving the chromosomes of the parent carrying the native (A. thaliana) CenH3.

Although GFPtailswap has yet to be tested directly in other plants, the GFPtailswap line of $A$. thaliana has been shown to generate haploids of Arabidopsis suecica a closely related species when crossed by $A$. suecica pollen. Its haploid-inducing effects - permitting the use of "haploid genetics" further enhance the power of Arabidopsis as a model system. As summarized in a recent review (Ravi et al., 2014), GFPtailswap has been employed to move an entire nuclear genome into a novel cytoplasmic background, to rapidly isolate mutants homozygous for several mutations (as homozygotes for $n$ loci segregate at a frequency of $1 / 2^{\mathrm{n}}$, rather than $1 / 4^{\mathrm{n}}$ ), to produce adult plants that are homozygous for maternal or paternally gametophyte-lethal mutations, and to rapidly convert tetraploids (from high-density tetraploid TILLING populations (Tsai et al., 2013)) to diploids.

It is clear that GFPtailswap technology can be tested in other cropsgiven the recent advances in targeted mutagenesis (Sander and Joung, 2014), it seems likely that any plant that can be transformed with this construct can be made defective in CenH3. Given our complete lack of understanding of how GFPtailswap induces its effect on chromosome segregation, it is difficult to say whether there might be some speciesspecificity to this effect. Aneuploids are frequently found among the progeny of GFPTailswap $\times$ wild-type crosses, and increasing the number of chromosomes over the relatively low number in Arabidopsis $(n=5)$ might reduce the frequency of perfect heterozygotes. Thus it remains to be determined whether this very efficient method for haploid induction in Arabidopsis can be translated to crop species.

\section{Insights into the genetics of haploid induction}

The donor plant genotype affects haploid induction and the subsequent embryo regeneration, as noted by their induction rates, in maize (Röber et al., 2005), onion (Allium cepa L.) (Alan et al., 2004; Bohanec and Jakse, 1999; Gioffriau et al., 1997), summer squash (Cucurbita pepo L.) (Shalaby, 2007) or sweetpotato (Ipomea batata (L.) Lam) (Kobayashi et al., 1993), which highlights the genotypic-specific response to gynogenesis. This maternal in vivo haploid induction ability in maize is a multi-genic trait (Deimling et al., 1997; Lashermes and Beckert, 1988; Röber et al., 2005) with a few major quantitative trait loci (QTL) and several small-effect QTL modifiers involved. The locus in situ gynogenesis (ggi1 for gynogenesis inducer 1) on chromosome 1 significantly affects the induction rate, though it shows segregation distortion against the inducer parent (Barret et al., 2008). One QTL in chromosome 1 accounts for up to $66 \%$ of the total genetic variance (Prigge et al., 2012). The QTL qhir1 has, however, a strong selective disadvantage due to a significant segregation distortion (Dong et al., 2013). More recently, Wu et al. (2014a) found that QTL qmhir1 and qmhir2 -which are on chromosomes 1 and 3 and explain $14.7 \%$ and $8.4 \%$ of the phenotypic variation, respectively- contribute to the maternal genetics of haploid induction in maize. Selection improves the haploid induction rate (Geiger and Gordillo, 2009; Prigge et al., 2012). Pyramiding major and modifier minor QTL may therefore assist on improving in vivo haploid induction, which is the backbone of DH technology in maize.

Highly efficient and reliable microspore culture protocols are available for many Brassica species (Ferrie and Möllers, 2011). There are, however, significant differences among genotypes in their embryogenic response of cultured microspores (Ferrie and Keller, 2007). Loci with additive effects seem to control this trait in Brassica crops (Zhang and Takahata, 2001), which shows a significant segregation distortion towards the alleles of the responsive cultivar (Cloutier et al., 1995).

Albinism remains a major hurdle to obtain haploids and $\mathrm{DH}$ in small grain cereals such as barley and wheat (Jauhar et al., 2009). This lack of chlorophyll results from plastid deficiency in albino plants due to nuclear genes interacting with pathways in plastid development (Torp et al., 2004). There are QTL for green plantlet in barley (Chen et al., 2007; Muñoz-Amatriaín et al., 2008), rye (Grosse et al., 1996), triticale (González et al., 2005; Krzewska et al., 2012) and wheat (Torp et al., 2001, 2004).

A total of 28 QTL localized on 5 chromosomes from A and R genomes control androgenic responsiveness in triticale (wheat $\times$ rye hybrid) anther culture (Krzewska et al., 2012). They account for 5.1\% to $21.7 \%$ of the phenotypic variation. Seven QTL on chromosomes 5A, 4R, 5R and $7 R$ are involved on androgenesis induction, while total and green regeneration ability are under control of genes localized on chromosome 4A. Some QTL affecting androgenesis efficiency are identical to those associated with androgenic embryo induction efficiency, thereby suggesting either tight linkage or pleiotropy between both.

Doubled haploids in barley can ensue from the uniparental elimination of chromosomes, after interspecific crosses between the cultigen (H. vulgare) and the wild related bulbous grass H. bulbosum. This haploid formation due to chromosome elimination depends on genetic factors (Ho and Kasha, 1975).

\section{Trait fixation (heterosis) via anther culture}

The economics of heterosis is limited by costs of hybrid seed production, and farmers purchasing these seeds every season to realize the yield potential of hybrid cultivars. The $\mathrm{DH}$ technique provides unique opportunity to develop lines that are truly homozygous and have excellent yields approaching hybrid cultivars. This proof of concept was demonstrated when some DH lines developed via anther culture from the heterotic $F_{1}$ crosses achieve the yield of heterotic hybrids in mutant crosses of barley (Kasha et al., 1977). Furthermore, Polok et al. (1997) isolated heterotic DH lines with yield potential similar to control cultivars, indicating the suitability of DH technique for the exploitation and fixation of heterosis. This approach was also used to select for heterotic DH lines from mutant crosses in rice, which out-yielded the better parents but with comparable performance to the heterotic $\mathrm{F}_{1} \mathrm{~s}$ ( $\mathrm{Ba}$ Bong and Swaminathan, 1995; Maluszynski et al., 2001). It was, however, noted the importance of dominance and additive genetic effects controlling grain yield parameters in the investigated populations. DH lines originating from heterotic $F_{1}$ crosses in wheat, when evaluated together with their respective parental lines and control, performed well and few transgressed significantly the higher yielding parent and the control cultivar (El-Hennawy et al., 2011). Clearly, these results demonstrate that DH lines derived from hybrid crosses can be used to extract lines with yield potential similar to hybrids (Bentolila et al., 1992).

\section{Unlocking new genetic variation}

Landraces are valuable plant genetic resources, which evolved over time and adapted to the natural environments, with high capacity to tolerate stress. They also yield reasonably well under low input production systems. The landraces are highly heterogeneous genepool (which 
could show some undesirable "genetic load") and may be excellent resources to identify new sources of variation associated with agronomically beneficial traits for use in plant breeding. Inbreeding unveils any genetic load, thus "cleaning" landraces lethal or detrimental alleles (Crnokrak and Barrett, 2002).

Inbred line development by recurrent selfing results in loss of variability at later generations in outbreeding species due to increased homozygosity. In vitro use of DH technology has been suggested to overcome this biological constraint (Reif et al., 2005). Unlocking the genetic diversity from highly heterogeneous landrace populations provides plant breeders a new opportunity to broaden the cultigen pool. For example, when comparing the phenotypic and molecular diversity in maize captured within DH lines derived from European landraces (Bugard, Gelber Badischer, Schindelmeiser) and their breeding value, Stringens et al. (2013) detected large genotypic variance among DH lines and identified lines with grain yields comparable to those of elite flint inbred lines, thus indicating the potential of DH technology to eliminate detrimental alleles from the landraces. Thus, the development of DH lines from landraces shows great promise to broaden and improve flint maize.

\section{Accelerating crop breeding using doubled haploids, DNA markers, and data management}

The development of crop cultivars by crossbreeding is both time and resource consuming. It takes between 8 to 10 years from the time the cross is made until phenotypically advanced uniform lines are produced. These are then evaluated for at least 3 years to identify potential candidate lines for cultivar release. The continued demand for new cultivars with specific characteristics requires that adopted plant breeding methods accelerate the development of the new cultivars. An offseason nursery reduces the development period of improved populations or advanced lines. This may be further shortened if seeds from the off-season nursery are harvested at near physiological maturity and immediately grown under controlled glasshouse conditions prior to growing under field conditions during the main crop season. At least six generations are needed to advance the lines with acceptable homozygosity levels prior to testing them for agronomic performance. Can this time be further shortened to develop homozygous lines with required characteristics?

The doubled haploid technology has been used in plant breeding and genomics research (Dunwell, 2010; Forster et al., 2007; Geng et al., 2013; Germanà, 2011; Jauhar et al., 2009; Li et al., 2013; Prasanna et al., 2012; Tuvesson et al., 2007). Furthermore, few known labs across continents support the large-scale induction of haploids, and some offer custom-made haploid inducers at affordable cost to support plant breeding programs in the developing world.

Most of our food staples are now genomic resources rich crops (Bolger et al., 2014; Dwivedi et al., 2007; Edwards and Batley, 2010; Edwards et al., 2013; Varshney et al., 2012), with many of their reference genomes sequenced (Bevan and Uauy, 2013; Feuillet et al., 2011). Crop genetic enhancers are now routinely using applied genomic tools to rapidly integrate various traits in new cultivars (Dwivedi et al., 2007; Collard and Mackill, 2008; Langridge and Fleury, 2011; Varshney et al., 2014). In this section, we provide an overview of the use of $\mathrm{DH}$, genomic technologies, and integrated data management to fasten the development of crop cultivars with specific attributes.

\subsection{Doubled haploids and marker assisted selection}

Both DH technology and marker-assisted selection (MAS) have independently the potential to shorten cultivar development time. The former requires only two seasons (or one season if microspore engineering and a new breeding technology such as Clustered Regularly Interspaced Short Palindromic Repeats [CRISPR] are employed) to develop homozygous lines (instead of six generations needed if crossbreeding is practiced), while the latter has the potential to pyramid many agronomically beneficial alleles simultaneously into improved genetic background and minimize field testing in early generations. MAS can be used as an indirect selection method to speed and increase the precision of the genetic progress, reduce the number of generations, and when integrated into optimized molecular breeding strategies, it can also lower the costs of selection (Dwivedi et al., 2007). Thus, integrating MAS with DH provides new opportunities for the development of improved selection methods that maximize selection gains and accelerate development of crop cultivars (Belicuas et al., 2007). Furthermore, Melchinger et al. (2011) indicated that MAS $F_{2}$ enrichment -in which $\mathrm{F}_{2}$ homozygous individuals for non-target alleles are discarded and carriers of target alleles are retained in the population- and subsequent MAS for high values of the marker score among DH lines derived from the selected $F_{2}$ individuals appears to be the best selection method for gene stacking.

DH and MAS technologies have been successfully employed to improve host plant resistance in cereal crops. For example, resistance to fusarium head blight (Fusarium graminearum) (Yang et al., 2003; http://www.eurotransbio.eu/lw_resource/datapool/_items/item_184/ shortwheat.pdf), stem rust (Puccinia graminis f. sp. tritici) (Mago et al., 2011; Wessels and Botes, 2014), and stripe rust (Puccinia striiformis f. sp. tritici) (Bakhtiar et al., 2014) in wheat; resistance to stripe rust (Puccinia striiformis f. sp. hordei.) in barley (http://barleyworld.org/sites/ default/files/bcd47amba.pdf); and resistance to blast (Magnaporthe oryzae B. Couch) and white-backed plant hopper (Sogatella furcifera) in rice (de Araújo et al., 2010; Yi et al., 2014). Fusarium head blight (Fusarium oxysporum $\mathrm{f}$. sp. conglutinans) is one of the most devastating diseases of cabbage (Brassica oleracea L. var. capitata) worldwide. Using MAS (InDel markers, Lv et al., 2013) and microspore culture (androgenesis), Lv et al. (2014) successfully developed DH lines combining improved agronomic characteristics and resistance to fusarium head blight that when crossed with elite cabbage inbred lines produced excellent highyielding fusarium head blight resistant hybrids. MAS is also being used in maize to breed new haploid inducer lines using the previously identified sources and markers for selection of haploids (Kebede et al., 2011; Li et al., 2009; Melchinger et al., 2013, 2014).

Haploid induction rate (HIR) is a quantitative trait in maize (see Section 9). A major quantitative trait loci (qhir1), which influences in vivo haploid induction (Prigge et al., 2012), was fine mapped to a $243 \mathrm{~kb}$ region based on analysis of the B73 reference genome using a large $F_{2}$ population derived from the cross $1680 \times$ UH400 to develop several closely linked markers (Dong et al., 2013). More recently, Dong et al. (2014) used these markers to develop candidate high oil inducer lines with an oil content of approximately $8.5 \%$ and HIR approximately $8 \%$, thus indicating that HIR selection along with MAS for qhir1 were effective to accelerate haploid induction in maize. The Centro Internacional de Mejoramiento de Maíz y Trigo (CIMMYT, Mexico) uses nowadays DH-based MAS with the aim of combining adaptation and host plant resistance to maize streak virus (Prasanna et al., 2012).

\subsection{Genomic selection using $\mathrm{DHs}$}

Genomic selection (Meuwissen et al., 2001) offers new opportunities for increasing the efficiency of plant breeding programs (Heffner et al., 2009; Nakaya and Isobe, 2012; Würschum et al., 2014). In this approach, the genome-wide marker data along with phenotyping are used to estimate genomic estimated breeding values (GEBVs) for predicting the performance. In comparison to MAS, which considers only significant marker-trait associations, genomic selection incorporates all marker information, thereby avoiding biased marker effect estimates and capturing more of the variation due to small-effect QTL. Genomic selection uses two types of data sets: a training set and a validation set. A training population with known GEBVs is needed to identify promising germplasm or cultivars with expected genomic value (predicted based on phenotype and GEBVs of the training populations) 
for making future gains in breeding programs. The training population represents lines that have been phenotyped and genotyped, while the prediction of GEBVs is carried out on lines that have only been genotyped. Several factors contribute to predicting the accuracy of the genomic selection, which include, inter alia, linkage disequilibrium, trait heritability, size of the training populations, number and type of markers, relationship between the training and test populations, and genotype $\times$ environment interaction (Crossa et al., 2014; Nakaya and Isobe, 2012; Zhong et al., 2009). Simulation studies in maize have clearly shown that response to genomic selection based on DHLs was greater than that of $F_{2}$ populations or marker-assisted recurrent selection (MARS) with varying numbers of QTL (Bernardo and Yu, 2007; Mayor and Bernardo, 2009a). Methods and statistical approaches to calculate GEBVs are available elsewhere (Da et al., 2014; Daetwyler et al., 2013; Lorenz, 2013; Resende et al., 2012; Zhao et al., 2014).

Albrecht et al. (2011) investigated the accuracy of genome-based prediction in testcross performance of 1380 DHLs of maize originating from 36 crosses, which were previously genotyped with 1152 SNPs, and included in multi-location trials for grain yield and grain dry matter content. They reported high average prediction accuracy based on genomic data for grain yield (0.72-0.74) among related families, while it decreased significantly $(0.47-0.480)$ when predictions were performed across distantly related families. Furthermore, they found that prediction accuracy decreased with decreasing sample size but was still high when the population size was halved (0.67-0.69).

The composition of training populations affects the prediction accuracy for lines from individual crosses. Riedelsheimer et al. (2013) genotyped 635 DHLs from five interconnected crosses involving four parents in maize with 16,741 SNPs and simultaneously evaluated these DHLs for agronomic traits. The five populations showed a genomic similarity pattern, which reflects the crossing scheme with a clear separation of full sibs, half sibs and unrelated groups. The prediction accuracy within full-sib families followed closely theoretical expectations, accounting for the influence of sample size and trait-heritability, while it declined by $42 \%$ if full-sib of DHLs were replaced by half-sib DHLs. Statistically significant better results could be achieved if half-sib DHLs were available from both instead of only one parent of the validation population. The unrelated crosses showing opposite linkage phases with validation population resulted in negative or reduced prediction accuracies, if used alone or in combination with related families, respectively. Parallel results on genomic prediction were also reported in maize breeding at CIMMYT (Crossa et al., 2014). It is therefore clear that DHLs are suitable for genomic selection.

\subsection{Establishing haploid induction facilities to support breeding programs}

Many breeding programs worldwide (particularly in the developing world) are limited by the technical knowhow or they lack facilities to apply DH technology for rapid generation of crop cultivars. The major steps involved in production and use of DH technology include haploid induction (in vitro or in vivo), haploid seed identification (using morphological or DNA markers), chromosome doubling of putative haploids (using colchicine treatment), and finally generation of $\mathrm{DH}$ seeds to produce DHLs. To date, multinational seed companies have their own facilities employing DH technology in large-scale production of inbred lines for development of hybrid cultivars. For example, DuPont Pioneer claims that just in 2011 more maize inbred lines were generated using DH technology than the total number of maize inbred lines generated in the first 80 years of their breeding program. Likewise, most of the canola or oilseed rape inbred lines that they bred in 2011 were generated through DH technology (www.pioneer.com/CMRoot/Pioneer/About_ Global/news_media/pannar/Double_Haploids.pdf). Such designated facilities have also come up globally to support public national breeding programs or small-medium private enterprises engaged in seed business. For example, CIMMYT Global Maize Program, in collaboration with the Institute of Plant Breeding, Seed Science and Population
Genetics of the University of Hohenheim (Germany) has established a state of the art haploid production facility at its experimental station in Agua Fría, Mexico to cater the needs of international maize improvement consortia operating in Asia (IMIC-Asia) and Latin America (IMIC-LA). More recently, CIMMYT has also established a DH facility at the Kenya Agricultural Research Institute in Kibokoto to support both private and public maize breeding programs in Africa. Through these facilities, CIMMYT either provides full or partial service (ranging from developing custom-based haploid inducers to developing DH lines) to breed inbred lines in maize (Prasanna et al., 2012). A feasibility study has been completed to establish a joint venture project between CIMMYT and Indian Institute of Horticultural Research (IIHR) at Bengaluru to set up a megafacility for induction of DHs in maize and sweet corn (and later on to expand this facility to several horticultural crops) using haploid inducer lines (Sadashiva et al., 2014). Such designated labs have been also set up in the industrialized world. For example, Iowa State University (USA) is offering DH technology for the development of maize inbred lines (www.plantbreeding.iastate.edu/DHF/DHF.htm), while the Heartland Plant Innovations (HPI) -a public private partnership- has established a DH laboratory at Manhattan, Kansas (USA) for use by public and private wheat breeders (Barkley and Chumley, 2012). HPI is currently engaged in developing a sorghum DH breeding systems to accelerate hybrid development. The Indian Council of Agricultural Research and the International Rice Research Institute (IRRI, Philippines) are working together on a DH laboratory at the Central Rice Research Institute in Cuttack, India (http://www.crri.nic.in/crri vision2030_2011.pdf) to cater the needs of rice breeding in this country. Further, a DH Service company, In vitro International (http://dbtncstcp. nic.in/html/Certified_TCUs/Vitro_International.html), Bengaluru, India with vast experience in $\mathrm{DH}$ of field crops (such as maize, mustard and canola) is planning to offer $\mathrm{DH}$ in vegetable crops for private sector seed companies in India (Sadashiva et al., 2014).

\subsection{Integrated data management}

An understanding and manipulation of the factors that influence plant growth, development and response to abiotic and biotic stresses is needed for the implementation of successful crop breeding programs. To do this, a comprehensive information system is needed to integrate and manage information in breeding and genetics research portfolios, i.e., mining germplasm for agronomically beneficial traits, gene discovery, functional marker development and precision environment profiling. With numerous tools available for curating, retrieving, integrating and mining of all breeding related- information, molecular breeding can be driven at the scale and depth that have never been possible. Opportunities exist to design and implement strong decision support systems, with appropriate tools and procedures, for enhancing the efficiency of crop breeding programs. Such a system will aid the breeders in selection of desirable recombinants through an optimum combination of phenotypic and genotypic information, as well as minimizing the population sizes, number of generations and overall costs while maximizing genetic gain for traditional and novel target traits (Xu et al., 2014).

One of today's tools for tomorrow's crops is the integrated breeding platform (IBP), which is a one-stop-shop through which user's access and download breeding informatics tools, procure services, access teaching and learning resources, and interact with their peers in various communities of practice. This web portal from the CGIAR Generation Challenge program (http://mbp.generationcp.org/) provides an online gateway particularly built for developing country crop breeders to ensure use of proven cutting-edge tools and techniques to improve breeding efficiency. The broad components of this IBP include the web-based portal, an open-source information and data management system comprising of an adaptable integrated breeding workflow system, and breeding and support services offering technical, professional and capacity building support to clients of the platform. The 
breeding management system (BMS) is the centerpiece of this portal, which consisted of suite of software applications and crop databases specifically designed to help breeders manage the logistic, data storage, statistical analysis and decision-making for integrated plant breeding. BMS comprises of mutually compatible interconnected data capture and quality assurance tools, comprehensive analytical toolboxes, and advanced decision-support tools, ensuring a seamless flow of information. Furthermore, it is customizable for different crops and breeding strategies (www.integratedbreeding.net/about-integrated-breedingplatform).

In summary, integrating DH technology with marker-aided breeding through both MAS and genomic selection, precision phenotyping, and integrated data management will accelerate and enhance the efficiency of plant breeding.

\section{Genetic gains through haploid breeding vis-à-vis other crossbreeding methods}

Genetic gains $\left(\Delta_{\mathrm{G}}\right)$ depend on additive genetic $\left(\sigma_{\mathrm{A}}^{2}\right)$ and phenotypic variances $\left(\sigma_{\mathrm{P}}^{2}\right)$, which are used to estimate a ratio known as narrow sense heritability $\left(\mathrm{h}^{2}=\sigma_{\mathrm{A}}^{2} / \sigma^{2}{ }_{\mathrm{P}}\right.$ ), selection intensity (or the percentage of individuals selected and advanced to the next generation), parental control of males and females (c), and time. The plant breeding equation for $\Delta_{\mathrm{G}}$ per cycle is $\left(\Delta_{\mathrm{C}}\right)=\mathrm{Kc} \mathrm{h} \mathrm{O}_{\mathrm{P}}$, where $\mathrm{K}$ is the selection differential in standard deviation units. The genetic gain per year $\left(\Delta_{\mathrm{G} / \mathrm{Y}}\right)$ is more informative than $\Delta_{C}$ when comparing alternative breeding schemes, and is estimated as $\Delta_{\mathrm{G} / \mathrm{Y}}=\left[\left(\mathrm{Kc}_{\mathrm{A}}^{2} \mathrm{~A}\right) /\left(\mathrm{Y} \sigma_{\mathrm{P}}\right)\right]$, where $\mathrm{Y}$ is the number of years required per cycle. Plant breeding maximizes $\Delta_{\mathrm{G}}$ by managing the components of this equation. The $\sigma^{2}{ }_{\text {A }}$ doubles while the dominant variance $\left(\sigma^{2}{ }_{D}\right)$ component of the $\sigma^{2}$ P disappears with DH technology. Likewise, as noted early by Griffing (1975), the advantage of haploid over diploid selection methods remains when measured on a per cycle basis and if total plant numbers are restricted, thus increasing the efficiency of recurrent selection (RS) methods. For example, grain yield of a synthetic maize population was the same as available hybrid cultivars after four cycles of RS involving DH technology (Valeriu et al., 2012).

Recurrent selection for combining ability with a tester using DHs (SDHT) with a 4-year cycle was more efficient than RS with testcrosses of $\mathrm{S}_{0}, \mathrm{~S}_{1}$ or $\mathrm{S}_{2}$ with or without the use of off-season nursery in an annual outcrossing crop such as maize (Bouchez and Gallais, 2000). This efficiency increases further with low $\mathrm{h}^{2}(<0.15)$, but the advantage of SDHT may reduce when using an off-season nursery or a constant effective population size. The $S_{1}$ testcross value may assist selecting the best families to extract $\mathrm{DH}$ lines because of their high correlation (Bordes et al., 2007). Mayor and Bernardo (2009a) indicated that DHs are better than a $F_{2}$ population in marker-assisted recurrent selection and genome-wide prediction of breeding values (or genomic selection) when many quantitative loci control the trait, $\mathrm{h}^{2}$ is low and the population size is small. Furthermore, multiple cycles of marker-assisted recurrent selection based on mapping quantitative trait loci in a $\mathrm{DH}$ population should lead to the same amount of genetic gain but at a lower cost than a two-stage DH testcross selection (Mayor and Bernardo, 2009b).

Various crossing schemes among inbred lines for early generation testing are used to predict the recombinant inbred line (RIL) distribution in inbreeding species. DH technology offers a methodology for estimating both the population mean and additive genetic variance, thus allowing cross prediction of inbred line distribution. Caligari and Powell (1985) found that DH system gave an accurate univariate cross prediction, but multivariate cross prediction based on $\mathrm{F}_{3}$ families had a more accurate ranking of crosses than the DH system (Powell et al., 1985 ) in barley breeding. Selecting the gamete donors may also shift the offspring performance in a desired direction, while postponing the generation for deriving DH should be weighed against any delays and additional costs (Iyamabo and Hayes, 1995). Bernardo (2009) argues that DHs in maize -an outcrossing species- should be induced from $\mathrm{F}_{2}$ instead of $F_{1}$ plants because such an approach does not delay inbred development, particularly if using a year-round nursery to get new $F_{1} s$ on a speculative basis.

De La Fuente et al. (2013) proposed an in vitro nursery approach to quickly produce homozygous and homogeneous lines by combining an offseason nursery (i.e., increasing generations per year) and DH technology (i.e., instant homozygosity per generation). In their approach, the tissues from selected genotypes are extracted and converted into a tissue culture, and after the somatic cells are stabilized in culture they are induced to undergo meiosis to get gametes that undergo mitotic cycles to get clonal cells. DNA is extracted from these cells for marker analysis and use in DNA marker-aided breeding methods such as marker-assisted backcrossing, marker-assisted recurrent selection or genome-wide prediction of breeding values. The outstanding gametes are selected and fused to form the new offspring. The selected new genotypes are thereafter converted into fertile plants or synthetic seeds for phenotyping, while the cell line is recycled in the nursery and induced to form new gametes, thus completing the breeding cycle.

\section{Perspectives}

Ninety years after the discovery of natural sporophytic haploids in Jimson weed and about 50 years after the breakthrough on the production of haploids from anther culture in Datura and the use of bulbosum method for haploid induction in barley, haploids and DHs are broadly used in breeding various crops. DH research has advanced considerably and facilitated the release of large number of cultivars, mostly in Brassica and cereals. Research led to great understanding of the genetics and mechanisms of haploid induction, identifying factors influencing haploid induction, finding useful markers (morphological, biochemical and DNA markers) to detect putative haploids, and increasing genetic gains through use of DH technology in plant breeding. The discovery of a highly efficient centromere-mediated genome elimination technique of haploid induction in Arabidopsis (Ravi and Chan, 2010; Ravi et al., 2014), has generated immense interest among researchers. Various research groups across globe are currently assessing its value in plant breeding. The greatest advantage of this technology is that the resulting DH plants, in some markets, may be free from regulatory burden as such plants carry the chromosomes derived only from the non-transgenic parent. Integration of DH technology together with applied genomics, off-season nursery and controlled environment facility provide new opportunities to maximize genetic gains in selection, economize breeding operations, and minimize cultivar development time. Multinational seed companies have widely adopted use of DH technology in largescale production of inbred lines for development of hybrid cultivars. It is encouraging to note that such facilities (though few in number at the present time) have also provided global support for public sector breeding programs or small-medium private enterprises engaged in seed business. Services provided by these platforms are on cost-basis and include partial or full support for the induction of haploids and their use in applied breeding.

In spite of all these developments there are still some challenges in use of DH technology that should be addressed. These include a better understanding of the molecular and cellular processes involved in haploid plant formation as well as genome doubling and their consequences; the need to establish DH technology, where it is not available currently (such as sorghum and soybean); increased efficiency in DH formation more efficient (including automated procedures); and development of novel strategies based on haploid and or DHs with regard to breeding of various crop species, germplasm enhancement, management of genetic resources, and development of novel types of experimental populations (Lubberstedt et al., 2015). Other relevant issues for further investigation include genotype-dependent response to androgenesis and occurrence of albino in in vitro culture, genetic switching from gametophytic to sporophytic phase during embryo production lacking fertilization, in vitro spontaneous production of 
DHs to avoid use of hazardous chemicals such as colchicine and epigenetic control of gene expression in gametogenesis, demonstrate the effectiveness of centromere-mediated genetic engineering for induction of haploids, as discovered in model plant Arabidopsis, in food crops with large genome size; and finally integrating DH technology into breeding pipeline beyond cereals and brassicas, e.g., banana, cassava, and pulses.

\section{Acknowledgment}

We appreciate the four anonymous reviewers for making useful suggestions on improving the manuscript. Sangam Dwivedi highly appreciates Ms Ishrath Durafsha of Knowledge Sharing and Innovation Program of ICRISAT for arranging reprints.

\section{References}

Åhman, I.M., Kazachkova, N.I., Kamnert, I.M., Hagberg, P.A., Dayteg, C.I., Eklund, G.M., et al., 2006. Characterization of transgenic oilseed rape expressing pea lectin in anthers for improved resistance to pollen beetle. Euphytica 151, 321-330.

Alan, A.R., Brants, A., Cobb, E., Goldschnied, P.A., 2004. Fecund gynogenic lines from onion (Allium cepa L.) breeding materials. Plant Sci. 167, 1055-1066.

Albrecht, T., Wimmer, V., Auinger, H.-J., Erbe, M., Knaak, C., Ouzunova, M., et al., 2011. Genome-based prediction of testcross values in maize. Theor. Appl. Genet. 123, 339-350.

Allshire, R.C., Karpen, G.H., 2008. Epigenetic regulation of centromeric chromatin: old dogs, new tricks? Nat. Rev. Genet. 9, 923-937.

Almouslem, A.B., Bommineni, V.R., Jauhar, P.P., Peterson, T.S., Rao, M.B., 1998. Haploid durum wheatproduction via hybridization with maize. Crop Sci. 38, 1080-1087.

Amrani, N., Sarrafi, A., Allibert, G., 1993. Genetic variability for haploid production in crosses between tetraploid and hexaploid wheats with maize. Plant Breed. 110, 123-128.

Araus, J.L., Cairns, J.E., 2014. Field high-throughput phenotyping: the new crop breeding frontier. Trends Plant Sci. 19, 52-61.

Aulinger, I.E., Peter, S.O., Schmid, J.E., Stamp, P., 2003. Rapid attainment of a doubled haploid line from transgenic maize (Zea mays L.) plants by means of anther culture. In Vitro Cell Dev. Biol. Plant 39, 165-170.

Ayed, O.S., de Buyser, J., Picard, E., Trifa, Y., Amara, H.S., 2010. Effect of pre-treatment on isolated microspores culture ability in durum wheat (Triticum turgidum subsp. durum Desf.). J. Plant Breed. Crop. Sci. 2, 30-38.

Ba Bong, B., Swaminathan, M.S., 1995. Magnitude of hybrid vigour retained in doubled haploid lines of some heterotic rice hybrids. Theor. Appl. Genet. 90, 253-257.

Bakhtiar, F., Afshari, F., Najafian, G., Mohammadi, M., 2014. Backcross breeding and double-haploid facilitated introgression of stripe rust resistance in bread wheat. Arch. Phytopathol. Plant Protect. 47, 1675-1685.

Ball, S.C., Zhou, H.P., Konzak, C.F., 1993. Influence of 2,4-D, IAA, and duration of callus induction in anther cultures of wheat. Plant Sci. 90, 195-200.

Barkley, A., Chumley, F.G., 2012. A doubled haploid laboratory for Kansas wheat breeding: an economic analysis of biotechnology adoption. Int. Food Agribus. Manag. Rev. 15, 99-119.

Barret, P., Brinkmann, M., Beckert, M., 2008. A major locus expressed in the male gametophyte with incomplete penetrance is responsible for in situ gynogenesis in maize. Theor. Appl. Genet. 117, 581-594.

Battistelli, G.M., Von Pinho, R.G., Justus, A., Couto, E.G.O., Balestre, M., 2013. Production and identification of doubled haploids in tropical maize. Genet. Mol. Res. 12, 4230-4242.

Belicuas, P.R., Guimarães, C.T., Paiva, L.V., Duarte, J.M., Maluf, W.R., Paiva, E., 2007. Androgenetic haploids and SSR markers as tools for the development of tropical maize hybrids. Euphytica 156, 95-102.

Bentolila, S., Hardt, T., Guitton, C., Freyssient, G., 1992. Comparative genetic analysis of $F_{2}$ plants and anther culture derived plants of maize. Genome 35, 575-582.

Bernardo, R., 2009. Should maize double haploids be induced among $F_{1}$ or $F_{2}$ plants? Theor. Appl. Genet. 119, 255-262.

Bernardo, R., Yu, J., 2007. Prospects of genomewide selection for quantitative traits in maize. Crop Sci. 47, 1082-1090.

Bevan, M.W., Uauy, C., 2013. Genomics reveals new landscape for crop improvement. Genome Biol. 14, 206. http://dx.doi.org/10.1186/gb-2013-14-6-206.

Bhojwani, S.S., Razdan, M.K., 1996. Plant Tissue Culture: Theory and Practice, a revised edition. Elsevier, Amsterdam (467 pp.).

Bitsch, C., Groger, S., Lelley, T., 1998. Effect of parental genotypes on haploid embryo and plantlet formation in wheat x maize crosses. Euphytica 103, 319-323.

Blakeslee, A.F., Belling, J., Farnham, M.E., Bergner, A.D., 1922. A haploid mutant in the Jimson weed, Datura stramonium. Science 55, 646-647.

Bohanec, B., Jakse, M., 1999. Variation of gynogenic response among long-day onion (Allium cepa L.) accessions. Plant Cell Rep. 18, 737-742.

Bolger, M.E., Weisshaar, Scholz U., Stein, N., Usadel, B., Mayer, K.F.X., 2014. Plant genome sequencing - applications for crop improvement. Trends Biotechnol. 26, 31-37.

Bordes, J., Charmet, G., Dumas de Vaulx, R., Lapierre, A., Pollacsek, M., Beckert, M., et al., 2007. Doubled-haploid versus single-seed descent and $S_{1}$-family variation for testcross performance in a maize population. Euphytica 154, 41-51.

Borrino, E., Powell, W., 1988. Stomatal guard-cell length as an indicator of ploidy in microspore-derived plants of barley. Genome 30, 158-160.
Bouchez, A., Gallais, A., 2000. Efficiency of the use of doubled-haploids in recurrent selection for combining ability. Crop Sci. 40, 23-29.

Brew-Appiah, R.A.T., Ankrah, N., Liu, W., von Wettstein, D., Rustgi, S., 2013. Generation of doubled haploid transgenic wheat lines by microspore transformation. PLoS One 11, e80155.

Burk, L.G., Gerstel, D.U., Wernsman, E.A., 1979. Maternal haploids of Nicotiana tabacum L. from seed. Science 206, 585.

Burnett, L., Yarrow, S., Huang, B., 1992. Embryogenesis and plant regeneration from isolated microspores of Brassica rapa L. ssp. oleifera. Plant Cell Rep. 11, 215-218.

Burr, B., Burr, F.A., Thompson, K.H., Alberston, M.C., Stubber, C.W., 1988. Gene mapping with recombinant inbreds in maize. Genetics 118, 519-526.

Burrack, L.S., Berman, J., 2012. Flexibility of centromere and kinetochore structures. Trends Genet. 28, 204-212.

Cai, D.T., Chen, D.T., Zhu, H., Jin, Y., 1988. In vitro production of haploid plantlets from the unfertilized ovaries and anther of Hubei photosynthetic genic male sterile rice (HPGMR). Acta Biochim. Exp. Sin. 21, 401-407.

Caligari, P.D.S., Powell, W., 1985. The use of doubled haploids in barley breeding. 2. Univariate cross prediction methods. Heredity 54, 53-358.

Caligari, P.D.S., Powell, W., Liddell, K., de Maine, M.J., Swan, G.E.L., 1988. Methods and strategies for detecting Solanum tuberosum dihaploids in interspecific crosses with S. phureja. Ann. Appl. Biol. 112, 323-328.

Campbell, A.W., Griffin, W.B., Conner, A.J., Rowarth, J.S., Burritt, D.J., 1998. The effects of temperature and light intensity on embryo numbers in wheat doubled haploid production through wheat $\times$ maize crosses. Ann. Bot. 82, 29-33.

Cardi, T., Earle, E.D., 1997. Production of new CMS Brassica oleracea by transfer of 'Anand' cytoplasm from B. rapa through protoplast fusion. Theor. Appl. Genet. 94, 204-212.

Cardoso, M.B., Bodanese-Zanettini, M.H., de Mundstock, E.C., Kaltchuck-Santos, E., 2007. Evaluation of gelling agents on anther culture: response of two soybean cultivars. Braz. Arch. Biol. Technol. 50, 933-939.

Castillo, A.M., Cistue, L., Valles, M.P., Sanz, J.M., Romagosa, I., Molina-Cano, J.L., 2001 Efficient production of androgenic doubled haploid mutants in barley by the application of sodium azide to anther and microspore culture. Plant Cell Rep. 20, 105-111.

Chaikam, V., Prasanna, V.M., 2012. Maternal haploid detection using anthocyanin markers. In: Prasanna, B.M. (Ed.), Doubled Haploid Technology in Maize Breeding. International Maize and Wheat Improvement Center, Mexico, pp. 20-23.

Chaikam, V., Nair, S.K., Babu, R., Martínez, L., Tejomurtula, J., Boddupalli, P.M., 2015. Analysis of effectiveness of $R 1 \mathrm{nj}$ anthocyanin marker for in vivo haploid identification in maize and molecular markers for predicting the inhibition of $R 1 \mathrm{nj}$ expression. Theor. Appl. Genet. 128, 159-171.

Chanana, N.P., Dhawan, V., Bhojwani, S.S., 2005. Morphogenesis in isolated microspore cultures of Brassica juncea. Plant Cell Tissue Organ Cult. 83, 169-177.

Chase, S.S., 1947. Techniques for isolating monoploid maize plants. J. Bot. 34, 582.

Chase, S.S., 1949. Monoploid frequencies in a commercial doubled cross hybrid maize and its component single cross hybrids and inbred lines. Genetics 34, 328-332.

Chase, S.S., 1969. Monoploids and monoploid derivatives of maize (Zea mays L.). Bot. Rev. 35, 117-167.

Chase, S.S., 2005. Utilization of haploids in plant breeding. In: Kasha, K.J. (Ed.), Proc. Int. Symp. Haploids in Higher Plants. Univ. Gulph, Ontario, Canada, pp. 211-230.

Chaudhary, H.K., Sethi, G.S., Singh, S., Pratap, A., Sharma, S., 2005. Efficient haploid induction in wheat by using pollen of Imperata cylindrica. Plant Breed. 124, 96-98.

Chauhan, H., Khurana, P., 2011. Use of doubled haploid technology for the development of stable drought tolerant bread wheat (Triticum aestivum L.) transgenics. Plant Biotechnol. J. 9, 408-417.

Chen, Y., 1986. The inheritance of rice pollen plant and its application in crop improvement. In: Hu, H., Yang, H. (Eds.), Haploids of Higher Plants In Vitro. Springer-Verlag, Berlin, pp. $118-136$

Chen, K., Gao, C., 2013. TALENs: customizable molecular DNA scissors for genome engineering of plants. J. Genet. Genomics 40, 271-279.

Chen, X.-W., Cistué, L., Muñoz-Amatriaín, M., Romagosa, S.M., Castillo, A.M., Vallés, M.P., 2007. Genetic markers for doubled haploid response in barley. Euphytica $158,287-294$

Chen, J.F., Cui, L., Malik, A.A., Mbira, K.G., 2011. In vitro haploid and dihaploid production via unfertilized ovule culture. Plant Cell Tissue Organ Cult. 104, 311-319.

Cheng, B.F., Séguin-Swartz, G., Somers, D.J., 2002. Cytogenetic and molecular characterization of intergeneric hybrids between Brassica napus and Orychophragmus violaceus. Genome $45,110-115$

Choe, E., Carbonero, C.H., Mulvaney, K., Rayburn, A.L., Mumm, R.H., 2012. Improving in vivo maize doubled haploid production efficiency through early detection of false positives. Plant Breed. 131, 399-401.

Choi, S.J., Kim, M.D., Cho, D.H., Hwang, B., Ahn, B.J., 1992. Gametosomatic hybridization through the fusion of Nicotiana tabacum mesophyll protoplasts $(2 \mathrm{n})$ and Petunia hybrida tetrad protoplasts (n). Kor. J. Plant Tissue Cult. 19, 241-247.

Christey, M.C., Makaroff, C.A., Earle, E.D., 1991. Atrazine resistant cytoplasmic male sterile nigra broccoli obtained by protoplast fusion between cytoplasmic male sterile Brassica olerace a and atrazine resistant B. campestris. Theor. Appl. Genet. 83, 201-208.

Chu, C., 1978. The N6 medium and its applications to anther culture of cereal crops. Proc Symp Plant Tissue Cult Peking. Science Press, pp. 43-50.

Chugh, A., Amundsen, E., Eudes, F., 2009. Translocation of cell-penetrating peptides and delivery of their cargoes in triticale microspores. Plant Cell Rep. 28, 801-810.

Cloutier, S., Cappadocia, M., Landry, B.S., 1995. Study of microspore culture responsiveness in oilseed rape (Brassica napus L.) by comparative mapping of a $F_{2}$ population and two microspore-derived populations. Theor. Appl. Genet. 91, 841-847.

Cobb, J.N., DeClerck, G., Greenberg, A., Clark, R., McCouch, S., 2013. Next generation phenotyping: requirements and strategies for enhancing our understanding of genotype-phenotype relationships and its relevance to crop improvement. Theor. Appl. Genet. 126, 867-887. 
Collard, B.C.Y., Mackill, D.J., 2008. Marker-assisted selection: an approach for precision plant breeding in the twenty-first century. Philos. Trans. R. Soc. Lond. B Biol. Sci. $363,557-572$.

Comai, L., 2014. Genome elimination: translating basic research into a future tool for plant breeding. PLoS Biol. 12, e1001876.

Cooper, J.L., Henikoff, S., 2004. Adaptive evolution of the histone fold domain in centromeric histones. Mol. Biol. Evol. 21, 1712-1718.

Corral-Martínez, P., Parra-Vega, V., Seguí-Simarro, J.M., 2013. Novel features of Brassica napus embryogenic microspores revealed by high pressure freezing and freez substitution: evidence for massive autophagy and excretion-based cytoplasmic cleaning. J. Exp. Bot. 64, 3061-3075.

Crnokrak, P., Barrett, S.C.H., 2002. Perspective: purging the genetic load: a review of the experimental evidence. Evolution 56, 2347-2358.

Croser, J., Lulsdorf, M., Davies, P., Wilson, J., Sidhu, P., Grewal, R., et al., 2005. Haploid embryogenesis from chickpea and field pea - Progress towards a routine protocol. In: Bennett, I.J., Bunn, E., Clarke, H., McComb, J.A. (Eds.), Contributing to Sustainable Future. Proceedings of the Conference of the Australian Branch of the International Association for Plant Tissue Culture and Biotechnology - Contributing to a Sustainable Future, Perth, Australia, pp. 71-82.

Croser, J.S., Lülsdorf, M.M., Davies, P.A., Clarke, H.J., Bayliss, K.L., Mallikarjuna, N., et al., 2006. Towards doubled haploid production in the Fabaceae: progress, constraints, and opportunities. Crit. Rev. Plant Sci. 25, 139-157.

Crossa, J., Pérez, P., Hickey, J., Burgueño, J., Ornella, L., Cerón-Rojas, J., et al., 2014. Genomic prediction in CIMMYT maize and wheat breeding programs. Heredity $112,48-60$.

Custers, J.B., Cordewener, J.H., Nollen, Y., Dons, H.J., Van Lockeren Campagne, M.M., 1994 Temperature controls both gametophytic and sporophytic development in microspore cultures of Brassica napus. Plant Cell Rep. 13, 267-271.

Da, Y., Wang, C., Wang, S., Hu, G., 2014. Mixed model methods for genomic prediction and variance component estimation of additive and dominance effects using SNP markers. PLoS One 9, e87666. http://dx.doi.org/10.1371/journal. pone.0087666

Daetwyler, H.D., Calus, M.P.L., Pong-Wong, R., de los Campos, G., Hickey, J.M., 2013. Genomic prediction in animals and plants: simulation of data, validation, reporting and benchmarking. Genetics 193, 347-365.

Daghma, D.S., Kumlehn, J., Hensel, G., Rutten, T., Melzer, M., 2012. Time-lapse imaging of the initiation of pollen embryogenesis in barley (Hordeum vulgare L.). J. Exp. Bot. 63, 6017-6021.

Daghma, D.E.S., Hensel, G., Rutten, T., Melzer, M., Kumlehn, J., 2014. Cellular dynamics during early barley pollen embryogenesis revealed by time-lapse imaging. Front. Plant Sci. 5 (Article 675).

Daofen, H., 1986. Jinghua No. 1, a winter wheat variety derived from pollen sporophyte. In: Hu, H., Yang, H. (Eds.), Haploids of Higher Plants In Vitro. Springer-Verlag, Berlin, pp. 137-148.

Datta, S.K., 2005. Androgenic haploids: factors controlling development and its application in crop improvement. Curr. Sci. 89, 1870-1878.

Davey, M.R., Blackhall, N.W., Lowe, K.C., Power, J.B., 1996. Gametosomatic hybridization. In vitro haploid production in higher plants. Curr. Plant Sci. Biotechnol. Agric. 24 309-320.

de Araújo, L.G., Prabhu, A.S., Pereira, P.A.A., de Silva, G.B., 2010. Marker assisted selection for the rice blast resistance gene Pi-ar in a backcross population. Crop Breed. Appl. Biotechnol. 10, 23-31.

De Buyser, J., Henry, Y., Lonnet, P., Hertzog, R., Hespel, A., 1987. Florin: a doubled haploid wheat variety developed by the anther culture method. Plant Breed. 98, 53-56.

De La Fuente, G.N., Frei, U.K., Lübberstedt, T., 2013. Accelerating plant breeding. Trends Plant Sci. 18, 667-672.

De Laat, A.M.M., Göhde, W., Vogelzang, M.J.D.C., 1987. Determination of ploidy of single plants and plant populations by flow cytometry. Plant Breed. 99, 303-307.

Deimling, S., Röber, F.K., Geiger, H.H., 1997. Methodology and genetics of in vivo haploid induction in maize. Vortr. Pflanzenzüchtg. 38, 203-224.

DePauw, R.M., Knox, R.E., Humphreys, D.G., Thomas, J.B., Fox, S.L., Brown, P.D., et al., 2011 New breeding tools impact Canadian commercial farmer fields. Czech J. Genet. Plant Breed. 47, S28-S34.

Desprez, B., Chupeau, M.C., Vermeulen, A., Delbreil, B., Chupeau, Y., Bourgin, J.P., 1995. Regeneration and characterization of plants produced from mature tobacco pollen protoplasts via gametosomatic hybridization. Plant Cell Rep. 14 204-209.

Diao, W.-P., Jia, Y.-Y., Song, H., Zhang, S.Q., Lou, Q.-F., Chen, J.-F., 2009. Efficient embryo induction in cucumber ovary culture and homozygous identification of the regenerants using SSR markers. Sci. Hortic. 119, 246-251.

Doležel, J. Greilhuber J., Suda, J., 2007. Flow cytometry with plants: an overview. In: Doležel, J., Greilhuber, J., Suda, J. (Eds.), Flow Cytometry with Plant Cells. Analysis of Genes, Chromosomes and Genomes. Wiley, Weinheim., pp. 41-65.

Dong, X., Xu, X., Miao, J., Li, L., Zhang, D., Mi, X., et al., 2013. Fine mapping of qhir1 influencing in vivo haploid induction in maize. Theor. Appl. Genet. 126, 1713-1720.

Dong, X., Xu, X., Li, L., Liu, C., Tian, X., Li, W., et al., 2014. Marker-assisted selection and evaluation of high oil in vivo haploid inducers in maize. Mol. Breed. 34, 1147-1158. http://dx.doi.org/10.1007/s11032-014-0106-3.

Doré, C., Prigent, J., Desprez, B., 1996. In situ gynogenetic haploid plants of chicory (Cichorium intybus L.) after intergeneric hybridization with Cicerbita alpina Walbr. Plant Cell Rep. 15, 758-761.

Dunwell, J.M., 1985. Embryogenesis from pollen in vitro. In: Zaitlin, M., Day, P., Hollaender, A. (Eds.), Biotechnology in Plant Science: Relevance to Agriculture in the Eighties. Academic Press, Orlando., pp. 49-76.

Dunwell, J.M., 2010. Haploids in flowering plants: origins and exploitation. Plant Biotechnol. J. 8, 377-424.
Dwivedi, S.L., Crouch, J.H., Mackill, D.J., Xu, Y., Blair, M.W., Ragot, M., et al., 2007. The molecularization of public sector crop breeding: progress, problems, and prospects. Adv. Agron. 95, 163-318.

Edwards, D., Batley, J., 2010. Plant genome sequencing: applications for crop improvement. Plant Biotechnol. J. 8, 2-9.

Edwards, D., Batley, J., Snowdon, R., 2013. Accessing complex crop genomes with nextgeneration sequencing. Theor. Appl. Genet. 126, 1-11.

Elhaddoury, J., Lhaloui, S., Udupa, S.M., Moatassim, B., Taiq, R., Rabeh, M., et al., 2012. Registration of Kharoba: a bread wheat cultivar developed through doubled haploid breeding. J. Plant Regist. 6, 169-173.

El-Hennawy, M.A., Abdalla, A.F., Shafey, S.A., Al-Ashkar, I.M., 2011. Production of doubled haploid wheat lines (Triticum aestivum L.) using anther culture technique. Ann. Agric. Sci. 56, 63-72.

Eudes, F., Shim, Y.-S., Jiang, F., 2014. Engineering the haploid genome of microspores. Biocatal. Agric. Biotechnol. 3, 20-23.

Evans, D.A., Sharp, W.R., Medina-Filho, H.P., 1984. Somaclonal and gametoclonal variation. Amer. J. Bot. 71, 759-774.

Ferrie, A.M.R., Keller, W.A., 2007. Optimization of methods for using polyethylene glycol as a non-permeating osmoticum for the induction of microspore embryogenesis in the Brassicaceae. In Vitro Cell Dev. Biol. Plant 43, 348-355.

Ferrie, A.M.R., Möllers, C., 2011. Haploids and doubled haploids in Brassica spp. for genetic and genomic research. Plant Cell Tissue Organ Cult. 104, 375-386.

Feuillet, C., Leach, J.E., Rogers, J., Schnable, P.S., Eversole, K., 2011. Crop genome sequencing: lessons and rationales. Cell 16, 77-87.

Fiorani, F., Schurr, U., 2013. Future scenarios for plant phenotyping. Ann. Rev. Plant Biol. 64, 267-291

Forster, B.P., Thomas, W.T.B., 2005. Doubled haploids in genetics and plant breeding. Plant Breed. Rev. 25, 57-87.

Forster, B.P., Heberle-Bors, E., Kasha, K.J., Touraev, A., 2007. The resurgence of haploids in higher plants. Trends Plant Sci. 12, 368-375.

Gamborg, O.L., Miller, R.A., Ojima, O., 1968. Nutrient requirements of suspension cultures of soybean root cell. Exp. Cell Res. 50, 151-158.

Garcia-Llamas, C., Ramirez, M.C., Ballesteros, J., 2004. Effect of pollinator on haploid production in durum wheat crossed with maize and pearl millet. Plant Breed. 123, 201-203.

Geiger, H.H., Gordillo, G.A., 2009. Doubled haploids in hybrid maize breeding. Maydica 54, 485-499.

Geiger, H.H., Schönleben, M., 2011. Incidence of male fertility in haploid elite dent maize germplasm. Maize Genet. Coop. Newl. 85, 22-32.

Geiger, H.H., Braun, M.D., Gordillo, G.A., Koch, S., Jesse, J., Krützfeldt, J., 2006. Variation for female fertility among haploid maize lines. Maize Genet. Coop. Newl. 80, 28-29.

Geng, X.X., Chen, S., Astarini, I.A., Yan, G.J., Tian, E., Meng, J., et al., 2013. Doubled haploids of novel trigenomic Brassica derived from various interspecific crosses. Plant Cell Tissue Organ Cult. 113, 501-511.

Germanà, M.A., 2011. Gametic embryogenesis and haploid technology as valuable support to plant breeding. Plant Cell Rep. 30, 839-857.

Giddings, G.D., Rees, H., 1992. A Nicotiana gametosomatic hybrid and its progenies. J. Exp. Bot. 43, 419-425

Gilkey, J.C., Staehelin, L.A., 1986. Advances in ultrarapid freezing for the preservation of cellular ultrastructure. J. Electron Microsc. Tech. 3, 177-210.

Gioffriau, E., Kahane, R., Rancillac, M., 1997. Variation of gynogenesis ability in onion (Allium cepa L.). Euphytica 94, 37-44.

Gioi, T.D., Tuan, V.D., 2002. Effect of different media and genotypes on anther culture efficiency of $F_{1}$ plants derived from crosses between IR64 and new plant type rice cultivars. Omonrice 10, 107-109.

Gomez-Pando, L.R., Jimnez-Davalos, J., Eguiluz-de La Barra, A., Aguilar-Castellanos, E., Falconí-Palomino, J., Ibañez-Termolada, M. et al., 2009. Estimated economic benefit of doubled haploid technique for Peruvian barley growers and breeders. Cereal Res. Commun. 37, 287-293.

González, J.M., Muñiz, L.M., Jouvne, N., 2005. Mapping of QTLs for androgenetic response based on a molecular genetic map of $x$ Tricosecale Wittmack. Genome 48, 999-1009.

Graf, R.J., Huel, P., Orshinsky, B.R., Kartha, K.K., 2003. McKenzie hard red spring wheat. Can. J. Plant Sci. 83, 565-569.

Graf, R.J., Beres, B.L., Laroche, A., Gaudet, D.A., Eudes, F., Pandeya, R.S., et al., 2013. Emerson hard red winter wheat. Can. J. Plant Sci. 93, 741-748.

Grauda, D., Lepse, N., Strazdina, V., Kokina, I., Lapina, L., Mikelsone, A., et al., 2010. Obtaining of doubled haploid lines by anther culture method for the Latvian wheat breeding. Agron. Res. 8, 545-552.

Greenblatt, I.M., Bock, M., 1967. A commercially desirable procedure for detection of monoploids in maize. J. Hered. 58, 9-13.

Grewal, R.K., Lulsdorf, M., Croser, J., Ochatt, S., Vandenberg, A., Warkentin, T.D., 2009. Doubled-haploid production in chickpea (Cicer arietinum L.): role of stress treatments. Plant Cell Rep. 28, 1289-1299.

Griffing, B., 1975. Efficiency changes due to use of doubled-haploids in recurrent selection methods. Theor. Appl. Genet. 46, 367-386.

Grosse, B.A., Deimling, S., Geiger, H.H., 1996. Mapping of genes for anther culture ability in rye by molecular markers. Vortr. Pflanzenzeuchtg. 35, 282-283.

Gu, H., Sheng, X., Zhao, Z., Yu, H., Wang, J., 2014. Initiation and development of microspore embryogenesis and plant regeneration of Brassica nigra. In Vitro Cell Dev. Biol. Plant $50,534-540$

Gugsa, L., Loerz, H., 2013. Male sterility and gametoclonal variations from gynogenically derived polyploids of tef (Erafrostis leff), Zucc. Trotter. African J. Plant Sci. 7, 53-60.

Gugsa, L., Sarial, A.K., Loerz, H., Kumlehn, J., 2006. Gynogenic plant regeneration from unpollinated flower explants of Eragrostis tef (Zuccagni) Trotter. Plant Cell Rep. 51, 1287-1293. 
Guha, S., Maheshwari, S.C., 1964. In vitro production of embryos from anthers of Datura. Nature 204, 497.

Guha, S., Maheshwari, S.C., 1966. Cell division and differentiation of embryos in the pollen grains of Datura in vitro. Nature 212, 97-98.

Gurushidze, M., Hensel, G., Heikel, S., Schedel, S., Valkov, V., Kumlehn, J., 2014. Truebreeding targeted gene knock-out in barley using designer TALE-nuclease in haploid cells. PLoS One 9, e92046.

Hamilton, J.P., Buell, C.R., 2012. Advances in plant genome sequencing. Plant J. 70 177-190.

Häntzschel, K.R., Weber, G., 2010. Blockage of mitosis in maize root tips using colchicinealternatives. Protoplasma 241, 99-104.

Heath, D.W., Earle, E.D., 1996. Synthesis of Ogura male sterile rapeseed (Brassica napus L.) with cold tolerance by protoplast fusion and effects of atrazine resistance on seed yield. Plant Cell Rep. 15, 939-944.

Heffner, E.L., Sorrells, M.E., Jannink, J.L., 2009. Genomic selection for crop improvement. Crop Sci. 49, 1-12.

Henikoff, S., Ahmad, K., Malik, H.S., 2001. The centromere paradox: stable inheritance with rapidly evolving DNA. Science 293, 1098-1102.

Ho, K.M., Jones, G.E., 1980. Mingo barley. Can. J. Plant Sci. 60, 279-280.

Ho, K.M., Kasha, K.J., 1975. Genetic control of chromosome elimination during haploid formation in barley. Genetics 81, 263-275.

Höfer, M., Gomez, A., Aguiriano, E., Manzanera, J.A., Bueno, M.A., 2002. Analysis of simple sequence repeat markers in homozygous lines of apple. Plant Breed. 121, 159-162.

Hofinger, B.J., Huynh, O.A., Jankowicz-Cieslak, J., Müller, A., Otto, I., Kumlehn, J., et al., 2013. Validation of doubled haploid plants by enzymatic mismatch cleavage. Plant Methods 9, 43 (http://www.plantmethods.com/content/9/1/43).

Houben, A., Sanei, M., Pickering, R., 2011. Barley doubled-haploid production by uniparental chromosome elimination. Plant Cell Tissue Organ Cult. 104, 321-327.

Hu, H., Zeng, J.Z., 1984. Development of new varieties via anther culture. In: Ammirato, P.V., Evans, D.A., Sharp, W.R., Yamada, Y. (Eds.), Hand Book of Plant Cell CultureCrop Species vol. 3. Macmillan, New York, pp. 65-90.

Humphreys, D.G., Townley-Smith, T.F., Czarnecki, E., Lukow, O.M., McCallum, B., Fetch, T., et al., 2006. Snowbird hard spring wheat. Can. J. Plant Sci. 86, 301-305.

Humphreys, D.G., Townley-Smith, T.F., Czarnecki, E., Lukow, O.M., Fofana, B., Gilbert, J., et al., 2007. Kanata hard white spring wheat. Can. J. Plant Sci. 87, 879-882.

Humphreys, D.G., Townley-Smith, T.F., Czarnecki, E., Lukow, O.M., McCallum, B., Fetch, T., et al., 2013. Snowstar hard white spring wheat. Can. J. Plant Sci. 93, 143-148.

Inagaki, M.N., Bohorova, N., 1995. Factors affecting the frequencies of embryo formation and haploid plant regeneration in crosses of hexaploid wheat with pearl millet. Breed. Sci. 45, 21-24.

Inoue, E., Sakuma, F., Kasumi, M., Hara, H., Tsukihashi, T., 2004. Maternal haploidization of Japanese pear through intergeneric hybridization with apple. Acta Horticult. 663, 815-818.

Iyamabo, O.E., Hayes, P.M., 1995. Effect of selection and opportunities for recombination in double-haploid populations of barley (Hordeum vulgare L.). Plant Breed. 114, 131-136.

Jacquard, C., Nolin, F., Hécart, C., Grauda, D., Rashal, I., Dhondt-Cordelier, S., et al., 2009. Microspore embryogenesis and programmed cell death in barley: effects of copper on albinism in recalcitrant cultivars. Plant Cell Rep. 28, 1329-1339.

Jain, S.M., Sopory, S.K., Veileux, R.E. (Eds.), 1996. In Vitro Haploid Production in Higher Plants vol. 1-5. Kluwer Academic Publishers.

Jauhar, P.P., Xu, S.S., Baenziger, P.S., 2009. Haploidy in cultivated wheat's: induction and utility in basic and applied research. Crop Sci. 49, 737-755.

Jones, A.M., Petolino, J.F., 1987. Effects of donor plant genotype and growth environment on anther culture of soft-red winter wheat (Triticum aestivum L.). Plant Cell Tissue Organ Cult. 8, 215-223.

Joosen, R., Cordewener, J., Supena, E.D.J., Vorst, O., Lammers, M., Maliepaard, C., et al., 2007. Combined transcriptome and proteome analysis identifies pathways and markers associated with the establishment of rapeseed microspore-derived embryo development. Plant Physiol. 144, 155-172.

Jorgensen, R.B., von Bothmer, R., 1988. Haploids of Hordeum vulgare and H. marinum from crosses between the two species. Hereditas 108, 207-212.

Kang, M., Hai, Y., Huang, B., Zhao, Y., Wang, S., Miao, L., et al., 2011. Breeding of newly licensed wheat variety Huapei 8 and improved breeding strategy by anther culture. Afr. J. Biotechnol. 10, 19701-19706.

Kapusi, E., Hensel, G., Coronado, M.J., Broeders, S., Marthe, C., Otto, I., et al., 2013. The elimination of a selectable marker gene in the doubled haploid progeny of cotransformed barley plants. Plant Mol. Biol. 149-160.

Kasha, K.J., Kao, K.N., 1970. High frequency haploid production in barley (Hordeum vulgare L.). Nature $225,874-876$.

Kasha, K.J., Song, L.S.P., Park, S.J., Reinbergs, E., 1977. 1977. Fixation of heterosis: comparison of $F_{1}$ hybrids with their respective homozygous lines developed using doubled haploid procedures. Cereal Res. Commun. 5, 205-214.

Kato, A., 2002. Chromosome doubling of haploid maize seedlings using nitrous oxide gas at the flower primordial stage. Plant Breed. 121, 370-377.

Kaur, P., Bhalla, J.K., 1998. Regeneration of haploid plants from microspore culture of pigeonpea (Cajanus cajan L.). Indian J. Exp. Biol. 36, 736-738.

Kebede, A.Z., Dhillon, B.S., Schipprack, W., Araus, J.L., Bänziger, M., Semagn, K., et al., 2011. Effect of source germplasm and season on the in vivo haploid induction rate in tropical maize. Euphytica 180, 219-226.

Khatun, R., Shahinul Islam, S.M., Ara, I., Tuteja, N., Bari, M.A., 2012. Effect of cold pretreatment and different media in improving anther culture response in rice (Oryza sativa L.) in Bangladesh. Indian J. Biotechnol. 11, 458-463.

Kobayashi, R.S., Sinden, S.L., Bouwkamp, J.C., 1993. Ovule cultures of sweet potato (Ipomoea batatas) and closely related species. Plant Cell Tissue Organ Cult. 32, 77-82.
Krzewska, M., Czyczyło-Mysza, I., Dubas, E., Gołebiowska-Pikania, G., Golemiec, E. Stojałowski, S., et al., 2012. Quantitative trait loci associated with androgenic responsiveness in triticale ( $x$ Triticosecale Wittm.) anther culture. Plant Cell Rep. 31, 2099-2108.

Kumlehn, J., Serazetdinova, L., Hensel, G., Becker, D., Loerz, H., 2006. Genetic transformation of barley (Hordeum vulgare L.) via infection of androgenetic pollen cultures with Agrobacterium tumefaciens. Plant Biotechnol. J. 4, 251-261.

Kynast, R.G., Davis, D.W., Phillips, R.L., Rines, H.W., 2012. Gamete formation via meiotic nuclear restitution generates fertile amphiploid $F_{1}$ (oat $\times$ maize) plants. Sex. Plant Reprod. 25, 111-122.

Labbani, Z., De Buyser, J., Picard, E., 2007. Effect of mannitol pretreatment to improve green plant regeneration on isolated microspore culture in Triticum turgidum ssp. durum cv. Plant Breed. 126, 565-568.

Langridge, P., Fleury, D., 2011. Making the most of 'omics' for crop breeding. Trends Biotechnol. 29, 33-40.

Lashermes, P., Beckert, M., 1988. Genetic control of maternal haploidy in maize (Zea mays L.) and selection of haploid inducing lines. Theor. Appl. Genet. 76, 404-410.

Laurie, D.A., 1989. The frequency of fertilization in wheat $\times$ pearl millet crosses. Genome 32, 1063-1067.

Laurie, D.A., Bennett, M.D., 1988. The production of haploid wheat plants from wheat $\times$ maize crosses. Theor. Appl. Genet. 76, 393-397.

Lee, C.H., Power, J.B., 1988a. Intraspecific gametosomatic hybridization in Petunia hybrida. Plant Cell Rep. 7, 17-18.

Lee, C.H., Power, J.B., 1988b. Intra- and interspecific gametosomatic hybridization within the genus Petunia. Plant Cell Tissue Organ Cult. 12, 197-200.

Li, A.M., Wei, C.X., Jiang, J.J., Zhang, Y.T., Snowdon, R.J., Wang, Y.P., 2009. Phenotypic variation in the progenies of somatic hybrids between Brassica napus and Sinapis alba. Euphytica 170, 289-296.

Li, H., Singh, R.P., Braun, H.J., Pfeiffer, W.H., Wang, J., 2013. Doubled haploids versus conventional breeding in CIMMYT wheat breeding programs. Crop Sci. 53, 74-83.

Li, H., Soriano, M., Cordewener, J., Muiño, J.M., Riksen, T., Fukuoka, H., et al., 2014. The histone deacetylase inhibitor Trichostatin A promotes totipotency in male gametophyte. Plant Cell 26, 195-209.

Liang, G.H., Xu, A., Tang, H., 1987. Direct generation of wheat haploids via anther culture. Crop Sci. 27, 336-339.

Liu, Y., Bassham, D.C., 2012. Autophagy: pathways for self-eating in plant cells. Ann. Rev. Plant Biol. 63, 215-217 (2012).

Liu, W., Ming, Y.Z., Polle, A.E., Konzak, C.F., 2002. Highly efficient doubled-haploid production in wheat (Triticum aestivum L.) via induced microspore embryogenesis. Crop Sci. 42, 686-692.

Liu, D., Zhang, H., Zhang, L., Yuan, Z., Hao, M., Zheng, Y., 2014. Distant hybridization: a tool for interspecific manipulation of chromosomes. In: Pratap, A., Kumar, J. (Eds.), Alien Gene Transfer in Crop Plants, Volume 1 Innovations, Methods and Risk Assessment. Springer, pp. 25-42.

Loo, S.-W., Xu, Z.H., 1986. Rice: anther culture for rice improvement in China. In: Bajaj, Y.P.S. (Ed.), Biotechnology in Agriculture and Forestry 2: Crops I. Springer-Verlag, Berlin, pp. 139-156.

Lorenz, A.J., 2013. Resource allocation for maximizing prediction accuracy and genetic gain of genomic selection in plant breeding: a simulation experiment. G3 3, 481-491.

Lubberstedt, T., Bohn, M., 2015. Competence center for doubled haploid research. XXII Plant and, January 10-14, 2015. San Diago, CA, USA, p. P0477.

Lv, H., Yang, L., Kang, J., Wang, Q., Wang, S., Fang, Z., et al., 2013. Development of InDel markers linked to Fusarium wilt resistance in cabbage. Mol. Breed. 32, 961-967.

Lv, H., Wang, Q., Yang, L., Fang, Z., Liu, Y., Zhuang, M., et al., 2014. Breeding of cabbage (Brassica oleracea L. var. capitata) with fusarium wilt resistance based on microspore culture and marker-assisted selection. Euphytica 200, 465-473.

Mago, R., Lawrence, G.J., Ellis, J.G., 2011. The application of DNA marker and doubled haploid technology for stacking multiple stem rust resistance genes in wheat. Mol. Breed. 27, 329-335.

Maheshwari, S., Tyagi, A.K., Malhotra, K., 1980. Induction of haploidy from pollen grains in angiosperms - the current status. Theor. Appl. Genet. 58, 193-206.

Maheshwari, S., Tan, E.H., West, A., Frankling, F.C.H., Comai, L., Chan, S.W.L., 2015. Naturally occurring differences in CENH3 affect chromosome segregation in zygotic mitosis of hybrids. PLoS Genet. 11, e1004970. http://dx.doi.org/10.1371/journal.pgen.1004970.

Malik, M.R., Wang, F., Dirpaul, J.M., Zhou, N., Polowick, P.L., Ferrie, A.M.R., et al., 2007 Transcript profiling and identification of molecular markers for early microspore embryogenesis in Brassica napus. Plant Physiol. 144, 134-154.

Malik, A.A., Cui, L., Zhang, S., Chen, J.-F., 2011. Efficiency of SSR markers for determining the origin of melon plantlets derived through unfertilized ovary culture. Hortic. Sci. (Prague) 38, 27-34.

Maluszynska, J., 2003. Cytogenetic tests for ploidy level analyses - chromosome counting In: Maluszynski, M., Kasha, K.J., Forster, B.P., Szarejko, I. (Eds.), Doubled Haploid Production in Crop Plants: A Manual. Kluwer Academic Publishers, Dordrecht. ISBN 1-4020-1544-5, pp. 391-395.

Maluszynski, M., Szarejko, I., Sigurbjörnsson, B., 1996. Haploid and mutation techniques In: Jain, S.M., Sopory, S.K., Veilleux, R.E. (Eds.), In Vitro Haploid production in Higher Plants, Vol 1: Fundamental Aspects and Methods. Kluwer Academic Publishers, Dordrecht, the Netherlands, pp. 67-93.

Maluszynski, M., Szarejko, I., Barriga, P., Balceryzk, A., 2001. Heterosis in crop mutant crosses and production of high yielding lines using doubled haploid systems. Euphytica 120 387-398.

Maluszynski, M., Kasha, K.J., Szarejko, I., 2003. Published protocols for other crop plant species. In: Maluszynski, M., Kasha, K.J., Forster, B.P., Szarejko, I. (Eds.), Doubled Haploid Production in Crop Plants: A Mannual. Kluwer Academic Publishers, Dordrecht, the Netherlands, pp. 309-336. 
Maraschin, S.F., Priester, W.D., Spaink, H.P., Wang, M., 2005. Androgenic switch: an example of plant embryogenesis from the male gametophyte perspective. J. Exp. Bot. 56, $1711-1726$

Maraschin, S.F., Caspers, M., Potokina, E., Wülfert, F., Graner, A., Spaink, H.P., et al., 2006. cDNA array analysis of stress-induced gene expression in barley androgenesis. Physiol. Plant. 127, 535-550.

Mayor, P.J., Bernardo, R., 2009a. Genomewide selection and marker-assisted recurrent selection in doubled haploid versus $F_{2}$ populations. Crop Sci. 49, 1719-1725.

Mayor, P.J., Bernardo, R., 2009b. Doubled haploids in commercial maize breeding: onestage and two-stage phenotypic selection versus marker-assisted recurrent selection. Maydica 54, 439-448.

Mba, C., Guimaraes, E.P., Ghosh, K., 2012. Re-orienting crop improvement for the changing climate conditions of the 21st century. Agric. Food Secur. 1, 7.

Melchinger, A.E., Technow, F., Dhillon, B.S., 2011. Gene stacking strategies with double haploids derived from biparental crosses: theory and simulations assuming a finite number of loci. Theor. Appl. Genet. 123, 1269-1279.

Melchinger, A.E., Schipprack, W., Würschum, T., Chen, S., Technow, F., 2013. Rapid and accurate identification of in vivo-induced haploid seeds based on oil content in maize. Sci. Rep. 3, 1-5.

Melchinger, A.E., Schipprack, W., Utz, H.F., Mirdita, V., 2014. In vivo haploid induction in maize: identification of haploid seeds by their oil content. Crop Sci. 54, 1497-1504.

Meuwissen, T.H.R., Hays, B.J., Goddard, M.E., 2001. Prediction of total genetic value using genome-wide dense marker maps. Genetics 157, 1819-1829.

Muñoz-Amatriaín, M., Svensson, J.T., Castill, A.M., Cistué, L., Close, T.J., Vallés, M.P., 2006 Transcriptome analysis of barley anthers: effect of mannitol treatment on microspore embryogenesis. Physiol. Plant. 127, 551-560.

Muñoz-Amatriaín, M., Castillo, A.M., Chen, X.W., Cistué, L., Vallés, M.P., 2008. Identification and validation of QTLs for green plant percentage in barley (Hordeum vulgare L.) anther culture. Mol. Breed. 22, 119-129.

Muñoz-Amatriaín, M., Svensson, J.T., Castill, A.M., Cistué, L., Close, T.J., Vallés, M.P., 2009. Transcriptome analysis of three barley lines after mannitol stress treatment reveals genes involved in genotype-dependent response to microspore embryogenesis. Funct. Integr. Genomics 9, 321-323.

Muranty, H., Sourdille, P., Bernard, S., Bernard, M., 2002. Genetic characterization of spontaneous diploid androgenetic wheat and triticale plants. Plant Breed. 121, 470-474.

Murashige, T., Skoog, F., 1962. A revised medium for rapid growth and bioassays with tobacco tissue cultures. Physiol. Plant. 15, 473-497.

Murovec, J., Bohanec, B., 2012. Haploids and doubled haploids in plant breeding. In: Abdurakhmonov, I. (Ed.), Plant Breeding. InTech Europe, Croatia. ISBN: 978-953-307932-5, pp. 87-106.

Murovec, J., Stajner, N., Jakse, J., Javornik, B., 2007. Microsatellite marker for homozygosity testing of putative doubled haploids and characterization of Mimulus species derived by a cross-genera approach. J. Amer. Soc. Hort. Sci. 132, 659-663.

Nakaya, A., Isobe, S.N., 2012. Will genomic selection be a practical method for plant breeding? Ann. Bot. 110, 1303-1316.

Nanda, D., Chase, S., 1966. An embryo marker for detecting monoploids of maize (Zea mays L.). Crop Sci. 6, 213-215

Narasimhulu, S.B., Kirti, P.B., Prakash, S., Chopra, V.L., 1992. Resynthesis of Brassica carinata by protoplast fusion and recovery of a novel cytoplasmic hybrid. Plant Cel Rep. $11,428-432$

Nitsch, J.P., Nitsch, C., 1969. Haploid plants from pollen grains. Science 163, 85-87.

Niu, Z., Jiang, A., Hammad, W.A., Oladzadabbasabadi, A., Xu, S.S., Mergoum, M., et al., 2014. Review of doubled haploid production in durum and common wheat through wheat $\times$ maize hybridization. Plant Breed. 133, 313-320. http://dx.doi. org/10.1111/pbr.12162.

Ochatt, S.J. 2008. Flow cytometry in plant breeding. Cytometry A 73, 581-598.

Palmer, C.E.D., Keller, W.A., Kasha, K., 2005. Haploids in Crop Improvement II. SpringerVerlag, Berlin Heidelberg.

Pauk, J., Janesó, Simon-Kiss, I., 2009. Rice doubled haploids and breeding. In: Touraev, A Foster, B.P., Jain, S.M. (Eds.), Advances in Haploid Production in Higher Plants. @ Springer Science + Business Media B.V., pp. 189-197.

Peloquin, S.J., Gabert, A.C., Ortiz, R., 1996. Nature of "pollinator" effect in potato (Solanum tuberosum) haploid production. Ann. Bot. 77, 539-542.

Pental, D., Mukhopadhyay, A., Grover, A., Pradhan, A.K., 1988. A selection method for the synthesis of triploid hybrids by fusion of microspore protoplasts $(n)$ with somatic cell protoplasts (2n). Theor. Appl. Genet. 76, 237-243.

Perera, P.I.P., Perera, L., Hocher, V., Verdil, J.-L., Yakandawala, D.M.D., Weerakoon, L.K 2008. Use of SSR markers to determine the anther-derived homozygous lines in coconut. Plant Cell Rep. 27, 1697-1703.

Perera, P.I.P., Ordoñez, C.A., Lopez-Lavalle, L.A.B., Dedicova, B., 2014. A milestone in the doubled haploid pathway of cassava. Protoplasma 251, 233-246.

Pickering, R.A., 1984. The influence of genotype and environment on chromosome elimination in crosses between Hordeum vulgare $\times$ Hordeum bulbosum. Plant Sci. Lett. 34, 153-164.

Pickering, R.A., Morgan, P.W., 1985. The influence of temperature on chromosome elimination during embryo development in crosses involving Hordeum spp., wheat (Triticum aestivum L.) and rye (Secale cereale L.). Theor. Appl. Genet. 70, 199-206.

Poland, J.A., Rife, T.W., 2012. Genotyping-by-sequencing for plant breeding and genetics. Plant Genomics 5, 92-102.

Polgári, D., Cseh, A., Szakács, E., Jäger, K., Molnár-Láng, M., Sági, L., 2014. High frequency generation and characterization of intergeneric hybrids and haploids from new wheat-barley crosses. Plant Cell Rep. 33, 1323-1331. http://dx.doi.org/10.1007/ s00299-014-1618-3.

Polok, K., Szarejko, I., Maluszynski, M., 1997. Barley mutant heterosis and fixation of $\mathrm{F}_{1}$ performance in doubled haploid lines. Plant Breed. 116, 133-140.
Powell, W., Caligari, P.D.S., McNicol, J.W., Jinks, J.L., 1985. The use of doubled haploids in barley breeding. 3. Multivariate cross prediction methods. Heredity $55,249-254$

Prasanna, B.M., Chaikam, V., Mahuku, G. (Eds.), 2012. Doubled Haploid Technology in Maize Breeding: Theory and Practice. CIMMYT, Mexico, D.F.

Prem, D., Gupta, K., Agnihotri, A., 2004. Doubled haploids: a powerful biotechnological tool for genetic enhancement in oilseed Brassicas. In: Srivastava, P.S., Narula, A., Srivastava, S. (Eds.), Plant Biotechnology and Molecular Markers. Anamaya Publishers, New Delhi, India, pp. 18-30.

Prem, D., Gupta, K., Agnihotri, A., 2005. Effect of various exogenous and endogenous factors on microspore embryogenesis in Indian mustard (Brassica juncea [L.] Czern \& Coss). In Vitro Cell Dev. Biol. Plant 41, 266-273.

Prem, D., Gupta, K., Sarkar, G., Agnihotri, A., 2008. Activated charcoal induced high frequency microspore embryogenesis and efficient doubled haploid production in Brassica juncea. Plant Cell Tissue Organ Cult. 93, 269-282.

Prem, D., Solís, M.T., Bárány, I., Rodríguez-Sanz, H., Risueño, M.C., Testillano, P.S., 2012. A new microspore embryogenesis system under low temperature which mimics zygotic embryogenesis initials, expresses auxin and efficiently regenerates doubled-haploid plants in Brassica napus. BMC Plant Biol. 12, 127 (http://www.biomedcentral.com/1471-2229/ 12/127).

Prigge, V., Xu, X., Li, L., Babu, R., Chen, S., Atlin, G.N., et al., 2012. New insights into the genetics of in vivo induction of maternal haploids, the backbone of doubled haploid technology in maize. Genetics 190, 781-793.

Raina, S.K., Zapata, F.J., 1997. Enhanced anther culture efficiency of indica rice (Oryza sativa L.) through modification of the culture media. Plant Breed. 116, 305-315.

Ravi, M., Chan, S.W.L., 2010. Haploid plants produced by centromere-mediated genome elimination. Nature 464, 615-619.

Ravi, M., Kwong, P.N., Menorca, R.M., Valencia, J.T., Ramahi, J.S., Stewart, J.L., et al., 2010. The rapidly evolving centromere-specific histone has stringent functional requirements in Arabidopsis thaliana. Genetics 186, 461-471.

Ravi, M., Shibata, F., Ramahi, J.S., Nagaki, K., Chen, C., Murata, M., et al., 2011. Meiosisspecific loading of the centromere-specific histone CENH3 in Arabidopsis thaliana. PLoS Genet. 7, e1002121.

Ravi, M., Marimuthu, M.P.A., Tan, E.H., Maheshwari, S., Henry, I.M., Marin-Rodriguez, B., et al., 2014. A haploid genetics toolbox for Arabidopsis thaliana. Nat. Commun. 5, 5334. http://dx.doi.org/10.1038/ncomms6334.

Reif, J.C., Hamrit, S., Heckenberger, M., Schipprack, W., Peter Maurer, H., Bohn, M., et al., 2005. Genetic structure and diversity of European flint maize populations determined with SSR analyses of individuals and bulks. Theor. Appl. Genet. 111, 906-913.

Reiss, E., Schubert, J., Scholze, P., Kramer, R., Sonntag, K., 2009. The barley thaumatin-like protein Hv-TLP8 enhances resistance of oilseed rape plants to Plasmodiophora brassicae. Plant Breed. 128, 210-212 (2009).

Ren, J.P., Dickson, M.H., Earle, E.D., 2000. Improved resistance to bacterial soft rot by protoplast fusion between Brassica rapa and B. oleracea. Theor. Appl. Genet. 100, 810-819.

Resende, M.F.R., Muñoz, P., Resende, M.D.V., Garrick, D.J., Fernando, R.L., Davis, J.M., et al., 2012. Accuracy of genomic selection methods in a standard data set of loblolly pine (Pinus taeda L.). Genetics 190, 1503-1510.

Reynolds, T.L., 1997. Pollen embryogenesis. Plant Mol. Biol. 33, 1-10.

Riedelsheimer, C., Endelman, J.B., Stange, M., Sorrells, M.E., Jannink, J.-C., Melchinger, A.E., 2013. Genomic predictability of interconnected biparental maize populations. Genetics 194, 493-503.

Röber, F.K., Gordillo, G.A., Geiger, H.H., 2005. In vivo haploid induction in maize-performance of new inducers and significance of doubled haploid lines in hybrid breeding. Maydica $50,275-283$.

Rokka, V.M., 2009. Potato haploids and breeding. In: Touraev, A., Forster, B.P., Jain, S.M. (Eds.), Advances in Haploid Production in Higher Plants. Springer, Netherlands, pp. 199-208

Sadashiva, A.T., Aghora, T.S., Rddy, M.K., Mohan, N., Rao, E.S., 2014. Growing interest in double haploidy for improvement of horticultural crops in India. Curr. Sci. 107, 16-17.

Sadasivaiah, R.S., Perkovic, S.M., Pearson, D.C., Postman, B., Beres, B.L., 2004. Registration of AC Andrew wheat. Crop Sci. 44, 696-697.

Salas, P., Revas-Sendra, A., Prohens, J., Seguí-Simarro, J.M., 2012. Influence of the stage for anther excision and heterostyly in embryogenesis induction from eggplant anther cultures. Euphytica 184, 235-250.

Sánchez-Díaz, R.A., Castillo, A.M., Vallés, M.P., 2013. Microspore embryogenesis in wheat: new marker genes for early, middle and late stages of embryo development. Sex. Plant Reprod. 26, 287-296.

Sander, J.D., Joung, J.K., 2014. CRISPR-Cas systems for editing, regulating and targeting genomes. Nat. Biotechnol. 32, 347-355.

Sanei, M., Pickering, R., Kumke, K., Nasuda, S., Houbeen, A., 2011. Loss of centromeric histone $\mathrm{H} 3$ (CENH3) from centromeres precedes uniparental chromosomal elimination in interspecific barley hybrids. Proc. Natl. Acad. Sci. U. S. A. 108, E498-E505.

Sangthong, R., Chin, D.P., Hayashi, M., Supaibulwattana, K., Mii, M., 2009a. Direct isolation of female germ units from ovules of Petunia hybrida by enzymatic treatment without releasing somatic protoplasts. Plant Biotechnol. J. 26, 369-375.

Sangthong, R., Chin, D.P., Supaibulwatana, K., Mii, M., 2009b. Gametosomatic hybridization between egg cell protoplast and mesophyll protoplast of Petunia hybrida. Plant Biotechnol. J. 26, 377-383.

Santra, M., Ankrah, N., Santra, D.K., Kidwell, K.K., 2012. An improved wheat microspore culture technique for the production of doubled haploid plants. Crop Sci. 52, 2314-2320.

Sarkar, D., Sharma, S., Chandel, P., Pandey, S.K., 2010. Evidence for gametoclonal variation in potato (Solanum tuberosum L.). Plant Growth Regul. 61, 109-117. 
Sãulescu, N.N., Ittu, G., Giura, A., Mustãtea, P., Ittu, M., 2012. Results of using Zea method for doubled haploid production in wheat breeding at NARD Fundulea, Romania. Rom. Agric. Res. 29 (http://www.incda-fundulea.ro/rar/ nr29/rar29.1.pdf).

Scheeren, P.L., da Rosa Caetano, V., Caierão, E., Silva, M.S., do Nascimento Jr., A., Eichelberger, L., et al., 2014. BSR 328 -doubled haploid bread wheat cultivar. Crop Breed. Appl. Biotechnol. 14, 65-67.

Seguí-Simarro, J.M., Nuez, F., 2008. How microspores transform into haploid embryos: changes associated with embryogenesis induction and microspore-derived embryogenesis. Physiol. Plant. 134, 1-12.

Seguí-Simarro, J.M., Testillano, P.S., Risueño, M.C., 2003. Hsp70 and Hsp90 change their expression and subcellular localization after microspore embryogenesis induction in Brassica napus L. J. Struct. Biol. 142, 379-391.

Shalaby, T.A., 2007. Factors affecting haploid induction through in vitro gynogenesis in summer squash (Cucurbita pepo L.). Sci. Hortic. 115, 1-6.

Sharma, S., Sethi, G.S., Chaudhary, H.K., 2005. Influence of winter and spring wheat genetic backgrounds on haploid induction parameters and trait correlation in the wheat $\times$ maize system. Euphytica 144, 199-205.

Shen, J.H., Li, M.F., Chen, Y.Q., Zhang, Z.H., 1982. Breeding by anther culture in rice varieties improvement. Sci. Agric. Sin. 2, 15-19.

Sigareva, M.A., Earle, E.D., 1997. Direct transfer of a cold-tolerant Ogura male-sterile cytoplasm into cabbage (Brassica oleracea ssp. capitata) via protoplast fusion. Theor. Appl. Genet. 94, 213-220.

Simmonds, J., 1989. Improved androgenesis of winter cultivars of Triticum aestivum L., in response to low temperature treatment of donor plants. Plant Sci. 65, 225-231.

Sitch, L.A., Snape, J.W., Firman, S.J., 1985. Intra-chromosomal mapping of crossability genes in wheat Triticum aestivum. Theor. Appl. Genet. 70, 309-314.

Skálová, D., Navarátilová, B., Doležalová, I., Vašut, R.J., Lebeda, A., 2012. Haploid and mixoploid cucumber (Cucumis sativus L.) protoplasts - isolation and fusion. J. Appl. Bot. Food Qual. 85, 64-72.

Snape, J.W., Sitch, L.A., Simpson, E., Parker, B.B., 1988. Tests for the presence of gametoclonal variation in barley and wheat doubled haploids produced using the Hordeum bulbosum system. Theor. Appl. Genet. 75, 509-513.

Sood, S., Dhawan, R., Singh, K., Bains, N., 2003. Development of novel chromosome doubling strategies for wheat $\mathrm{x}$ maize system of wheat haploid production. Plant Breed. 122, 493-496

Stringens, A., Schipprack, W., Reif, J.C., Melchinger, A., 2013. Unlocking the genetic diversity of maize landraces with doubled haploids opens new avenues for breeding. PLoS One 8, e57234. http://dx.doi.org/10.1371/journal.pone.0057234.

Sun, Y.Q., Zhang, X.L., Nie, Y.C., Guo, X.P., Jin, S.X., Liang, S.G., 2004. Production and characterization of somatic hybrids between upland cotton (Gossypium hirsutum) and wild cotton (G. klotzschianum Anderss). Theor. Appl. Genet. $109,472-479$

Sun, Y.Q., Zhang, X.L., Nie, Y.C., Guo, X.P., 2005. Production of fertile somatic hybrids of Gyssypium hirsutum + G. bickii and G. hirusutum + G. stockii via protoplast fusion. Plant Cell Tissue Organ Cult. 83, 303-310.

Sun, Y., Nie, Y., Guo, X., Huang, C., Zhang, X., 2006. Somatic hybrid between Gyssypium hirsutum L. $(4 \times)$ and G. davidsonii Kellog $(2 \times)$ produced by protoplast fusion. Euphytica 151, 393-400.

Sundberg, E., Landgren, M., Glimelius, K., 1987. Fertility and chromosome stability in Brassica napus resynthesized by protoplast fusion. Theor. Appl. Genet. 75, 96-104 (1987).

Swanson, W.J., Vacquier, V.D., 2002. The rapid evolution of reproductive proteins. Nat. Rev. Genet. 3, 137-144.

Szarejko, I., Forster, B.P., 2007. Doubled haploidy and induced mutation. Euphytica 158, 359-370.

Tadesse, W., Inagaki, M., Tawkaz, S., Baum, M., van Ginkel, M., 2012. Recent advances and application of doubled haploids in wheat breeding. Afr. J. Biotechnol. 11, 15484-15492.

Takahata, Y., Brown, D.C.W., Keller, W.A., 1991. Effect of donor plant age and inflorescence age on microspore culture of Brassica napus L. Euphytica 58, 51-55.

Tang, F., Tao, Y., Zhao, T., Wang, G., 2006. In vitro production of haploid and doubled haploid plants from pollinated ovaries of maize (Zea mays L.). Plant Cell Tissue Organ Cult. 84, 233-237 (2006).

Tek, A.L., Stupar, R.M., Nagaki, K., 2014. Modification of centromere structure: a promising approach for haploid line production in plant breeding. Turk. J. Agric. For. 2014, 38 http://dx.doi.org/10.3906/tar-1405-137.

Thomas, W.T.B., Gertson, B., Forster, B.P., 2003. Doubled haploids in breeding. In: Maluszynski, M., Kasha, K.J., Forster, B.P., Szarejko, I. (Eds.), Doubled Haploid Production in Crop Plants: A Manual. Kluwer Academic Publ., Dordrecht, the Netherlands, pp. 337-350.

Thompson, K.F., 1972. Oilseed rape. Reports of the Plant Breeding Institute. Cambridge University Press, Cambridge, pp. 94-96.

Thudi, M., Li, Y., Jackson, S.A., May, G.D., Varshney, R.K., 2012. Current state-of-art of sequencing technologies for plant genomics research. Brief. Funct. Genomics 2, 3-11.

Torp, A.M., Hansen, A.L., Andersen, S.B., 2001. Chromosomal regions associated with green plant regeneration in wheat (Triticum aestivum L.) anther culture. Euphytica 119, 377-387.

Torp, A.M., Bekesiova, I., Holme, I.B., Hansen, A.L., Andersen, S.B., 2004. Genetics related to doubled haploid induction in vitro. In: Mujib, A. (Ed.), In Vitro Application in Crop Improvement. Science Publishers, Plymouth, United Kingdom, pp. 34-52.

Touraev, A., Stoger, E., Voronin, V., Heberle-Bors, E., 1997. Plant male germ line transformation. Plant J. 12, 949-956.
Tsai, H., Missirian, V., Ngo, K.J., Tran, R.K., Chan, S.R., Sundaresan, V., et al., 2013. Production of a high-efficiency TILLING population through polyploidization. Plant Physiol. 161, 1604-1614.

Tsuwamoto, R., Fukuoka, H., Takahata, Y., 2007. Identification and characterization of genes expressed in early embryogenesis from microspores of Brassia napus. Planta $225,641-652$

Tu, Y.Q., Sun, J., Ge, X.H., Li, Z.Y., 2009. Chromosome elimination, addition and introgression in intertribal partial hybrids between Brassica rapa and Isatis indigotica. Ann. Bot. 103, 1039-1048.

Tuvesson, S., Dayteg, C., Hagberg, P., Manninen, O., Tanhuanpää, P., Tenhola-Roininen, T., et al., 2007. Molecular markers and double haploids in European plant breeding programmes. Euphytica 158, 305-312.

Valeriu, R., Georgeta, D., Mihail, M., Daniel, S., 2012. Selection and breeding experiments at the haploid level in maize (Zea mays L.). J. Plant Breed. Crop. Sci. 4, 72-79.

Varshney, R.K., Nayak, S.N., May, G.D., Jackson, S.A., 2009. Next-generation sequencing technologies and their implications for crop genetics and breeding. Trends Biotechnol. 27, 522-530.

Varshney, R.K., Kudapa, H., Roorkiwal, M., Thudi, M., Pandey, M.K., Saxena, R., et al., 2012. Advances in genetics and molecular breeding of three legume crops of semi-arid tropics using next generation sequencing and high throughput genotyping technologies. J. Biosci. 37, 811-820.

Varshney, R.K., Roorkiwal, M., Nguyen, H.T., 2013. Legume genomics: from genomic resources to molecular breeding. Plant Genomics 6. http://dx.doi.org/10.3835/ plantgenome2013.12.0002in.

Varshney, R.K., Terauchi, R., McCouch, S.R., 2014. Harvesting the promising fruits of genomics: applying genome sequencing technologies to crop breeding. PLoS Biol. 12, e1001883. http://dx.doi.org/10.1371/journal.pbio.1001883.

Wang, C.C., Kuang, B.J., 1981. Induction of haploid plants from the female gametophyte of Hordeum vulgare L. Acta Bot. Sin. 23, 329-330.

Weber, S., Wilfried, L., Friedt, W., 2004. Efficient doubled haploid production in Brassica napus via microspore colchicine treatment in vitro and ploidy determination by flow cytometry. Weber-Lühs-Friedt GCIRC-Bulletinpp. 1-6.

Wessels, E., Botes, W.C., 2014. Accelerating resistance breeding in wheat by integrating marker-assisted selection and doubled haploid technology. South Afr. J. Plant Soil 31, 35-43.

Wu, P., Li, H., Ren, J., Chen, S., 2014a. Mapping of maternal QTLs for in vivo haploid induction rate in maize (Zea mays L.). Euphytica 196, 413-421.

Wu, P., Ren, J., Li, L., Chen, S., 2014b. Early spontaneous diploidization of maternal maize haploids generated by in vivo haploid induction. Euphytica 200, 127-138.

Würschum, T., Tucker, M.R., Reif, J.C., Maurer, H.P., 2012. Improved efficiency of doubled haploid generation in hexaploid triticale by in vitro chromosome doubling. BMC Plant Biol. 12, 109 (http://www.biomedcentral.com/14712229/12/109).

Würschum, T., Abel, S., Zhao, Y., 2014. Potential of genomic selection in rapeseed (Brassica napus L.) breeding. Plant Breed. 133, 45-51.

Xu, L., Najeeb, U., Tang, G.X., Gu, H.H., Zhang, G.Q., 2007. Haploid and doubled haploid technology. Adv. Bot. Res. 45, 181-216. http://dx.doi.org/10.1016/ S0065-2296(07)45007-8.

Xu, Y., Wan, J., Prasanna, B.M., 2014. Breeding informatics of crop improvement: current status and prospects. Plant Animal Genome XXII Conference. January 11-15, 2014, San Diego, California, p. W 379 (www.intlpag.org).

Yang, X., Fu, H., 1989. Hua03 - a high protein indica rice. Int. Rice Res. Newsl. 14 14-15.

Yang, Z.P., Gilbert, J., Somers, D.J., Fedak, G., Procunier, J.D., McKenzie, I.H., 2003. Marker assisted selection of fusarium head blight resistance genes in two double haploid populations of wheat. Mol. Breed. 12, 309-317.

Yi, G., Lee, H.-S., Kim, K.-M., 2014. Improved marker-assisted selection efficiency of multiresistance in doubled haploid rice plant. Euphytica http://dx.doi.org/10.1007/s10681014-1303-1.

Ying, C., Chofu, L., Yunbi, X., Ping, H., Lihuang, Z., 1996. Gametoclonal variation of microspore derived doubled haploids in indica rice agronomic performance isozymes and RFLP analysis. J. Genet. Genomics 23, 196-204.

Yoshida, S., Watanabe, K., Fujino, M., 1998. Non-random gametoclonal variation in rice regenerants from callus subcultured for a prolonged period under high osmotic stress. Euphytica 104, 87-94.

Zaki, M.A., Dickinson, H.G., 1990. Structural changes during the first divisions of embryos resulting from anther and free microspore culture in Brassica napus. Protoplasma 156 149-162.

Zhang, F.L., Takahata, Y., 2001. Inheritance of microspore embryogenic ability in Brassica crops. Theor. Appl. Genet. 103, 254-258.

Zhang, L.Q., Yen, Y., Zhang, Y.L., Liu, D.C., 2007. Meiotic restriction in emmer wheat is controlled by one or more nuclear genes that continue to function in derived lines. Sex. Plant Reprod. 20, 159-166.

Zhang, L., Zhang, L., Luo, J., Chen, W., Hao, M., Liu, B., et al., 2011. Synthesizing double haploid hexaploid wheat populations based on a spontaneous alloploidization process. J. Genet. Genomics 38, 89-94.

Zhao, Y., He, X., Wang, J., Liu, W., 1990. Anther culture 28 - a new disease resistant and high-yielding variety of winter wheat. In: Bajaj, Y.P.S. (Ed.), Biotechnology in Agriculture and Forestry 13: Wheat. Springer-Verlag, Berlin, pp. 353-362.

Zhao, J., Newcomb, W., Simmonds, D., 2003. Heat-shock proteins 70 kDa and 19 kDa are not required for induction of embryogenesis of Brassica napus L. cV. Topas microspores. Plant Cell Physiol. 44, 1417-1421.

Zhao, Y., Mette, M.F., Gowda, M., Longin, C.F.H., Reif, J.C., 2014. Bridging the gap between marker-assisted and genomic selection of heading time and plant height in hybrid wheat. Heredity 112, 638-6645. 
Zhong, S., Dekkers, J.C.M., Fernando, R.L., Jannink, J.-L., 2009. Factors affecting accuracy from genomic selection in populations derived from multiple inbred lines: a barley case study. Genetics 182, 355-364.

Zhou, C., Yang, H.Y., 1981. Studies on the in vitro induction of callus from embryo sacs of rice. Hereditas 3, 10-12.

Zhu, D., Pan, X., 1990. Rice (Oryza sativa L.): Guan 18 - an improved variety through anther culture. In: Bajaj, Y.P.S. (Ed.), Biotechnology in Agriculture and Forestry 2: Haploids in Crop Improvement I. Springer-Verlag, Berlin, pp. 204-211.
Żur, I., Dubas, E., Krzewska, M., Sánchez-Díaz, R.A., Castillo, A.M., Vallés, M.P., 2014. Changes in gene expression patterns associated with microspore embryogenesis in hexaploid triticale ( $x$ Triticosecale Wittm.). Plant Cell Tissue Organ Cult. 116, 261-267. http://dx.doi.org/10.1007/s11240-013-0399-7. 